\title{
ABTS/PP Decolorization Assay of Antioxidant Capacity Reaction Pathways
}

\author{
Igor R. Ilyasov*, Vladimir L. Beloborodov, Irina A. Selivanova and Roman P. Terekhov
}

Department of Chemistry, Sechenov First Moscow State Medical University, Trubetskaya Str. 8/2, 119991

Moscow, Russia; vlbe@list.ru (V.L.B.); irinaselivanova@yandex.ru (I.A.S.); r.p.terekhov@yandex.ru (R.P.T.)

* Correspondence: igor@ilyasov.net; Tel.: +7-985-764-0744

Received: 30 November 2019; Accepted: 5 February 2020; Published: 8 February 2020

\begin{abstract}
The 2,2' -azino-bis(3-ethylbenzothiazoline-6-sulfonic acid) $\left(\mathrm{ABTS}^{\bullet+}\right)$ radical cation-based assays are among the most abundant antioxidant capacity assays, together with the 2,2-diphenyl-1picrylhydrazyl (DPPH) radical-based assays according to the Scopus citation rates. The main objective of this review was to elucidate the reaction pathways that underlie the ABTS/potassium persulfate decolorization assay of antioxidant capacity. Comparative analysis of the literature data showed that there are two principal reaction pathways. Some antioxidants, at least of phenolic nature, can form coupling adducts with $\mathrm{ABTS}^{\bullet+}$, whereas others can undergo oxidation without coupling, thus the coupling is a specific reaction for certain antioxidants. These coupling adducts can undergo further oxidative degradation, leading to hydrazindyilidene-like and/or imine-like adducts with 3-ethyl-2-oxo-1,3-benzothiazoline-6-sulfonate and 3-ethyl-2-imino-1,3-benzothiazoline-6-sulfonate as marker compounds, respectively. The extent to which the coupling reaction contributes to the total antioxidant capacity, as well as the specificity and relevance of oxidation products, requires further in-depth elucidation. Undoubtedly, there are questions as to the overall application of this assay and this review adds to them, as specific reactions such as coupling might bias a comparison between antioxidants. Nevertheless, ABTS-based assays can still be recommended with certain reservations, particularly for tracking changes in the same antioxidant system during storage and processing.
\end{abstract}

Keywords: ABTS; TEAC; antioxidant capacity; coupling reaction; adducts formation; flavonoids; quercetin; taxifolin

\section{Introduction}

It has been more than two decades since one of the most widely used methods of antioxidant capacity measurement, the improved trolox equivalent antioxidant capacity (TEAC) assay, was invented [1]. This assay applies the radical cation ABTS ${ }^{\bullet+}\left(2,2^{\prime}\right.$-azino-bis(3-ethylbenzothiazoline-6sulfonic acid) as a model radical and differs from the initial version of TEAC assay in a radical-initiatorpotassium persulfate (PP) instead of metmyoglobin/ $\mathrm{H}_{2} \mathrm{O}_{2}$ [2]. A recently published comprehensive overview of ABTS/TEAC assays gives an overall insight into $\mathrm{ABTS}^{\bullet+}$ radical cation-based antioxidant capacity approaches, including different methods of $\mathrm{ABTS}^{\bullet+}$ generation, quantification strategies, and experimental design, among others, as well as a considerable TEAC value data collection obtained using the $\mathrm{ABTS}^{\bullet+}$ chromogen [3]. It can be assuredly stated that the ABTS/PP assay measures only the antioxidant capacity, does not estimate the antioxidant reactivity or concurrent inhibition rates, and it has some shortcomings, which are out of the scope of this work and are comprehensively enlightened in the recent reviews, for instance, Cano et al. [3], Schaich et al. [4], or Apak [5]. This review focuses on another issue, namely, on what happens with $\mathrm{ABTS}^{\bullet+}$, as well as with antioxidants, as a result of their interaction. Thus, the main objective of this review was to elucidate the pathways of ABTS ${ }^{\bullet+}$ with antioxidants reactions. Due to many different TEAC assay modifications, widespread use of 
Trolox as an equivalent standard compound, and the TEAC index as a measure for antioxidant capacity expression in different assays, we here use the abbreviation "ABTS/PP" for the improved TEAC assay.

\section{ABTS/PP Abundance Statistics}

Despite the recent numerous reviews on the measurement of antioxidant activity/antioxidant capacity (AOA/AOC) [6-14] and even the emergence of a systematizing, comprehensive, and fundamental book devoted to this issue [15], the choice of a method for the study of AOA/AOC remains difficult, as none of the developed methods are recognized as universal. However, we can still say that at the moment the circle of the most widely used in vitro AOA/AOC methods is outlined, among which the ABTS/PP method has a special place (Table 1). According to the Scopus citation indexes, ABTS-based antioxidant capacity assays are among the three most popular methods, together with 2,2-diphenyl-1-picrylhydrazyl (DPPH)-based and ferric-reducing antioxidant power (FRAP). All three are commonly accepted and routinely practiced in research laboratories throughout the world.

Table 1. The citation rates of the most widely used antioxidant activity/antioxidant capacity (AOA/AOC) methods and frequency of abbreviation usage. Data are from the Scopus database. ABTS: 2,2'-azino-bis(3-ethylbenzothiazoline-6-sulfonic acid), PP: potassium persulfate.

\begin{tabular}{|c|c|c|c|}
\hline Method & $\begin{array}{c}\text { References of } \\
\text { Basic Publications }\end{array}$ & $\begin{array}{l}\text { Citation } \\
\text { Rate }^{1}\end{array}$ & $\begin{array}{l}\text { Frequency of Abbreviation Use } \\
\text { (Keywords Used) }\end{array}$ \\
\hline TEAC & {$[1,2,16]$} & 13,220 & $\begin{array}{l}37722^{2} \text { ("TEAC" or “Trolox equivalent } \\
\text { antioxidant capacity") since } 1993\end{array}$ \\
\hline $\begin{array}{c}\text { ABTS/PP } \\
\text { decolorization assay }\end{array}$ & [1] & 9845 & $\begin{array}{c}10,109 \text { ("ABTS antioxidant" or "ABTS } \\
\text { antiradical" or "ABTS radical scavenging") } \\
\text { since } 1988\end{array}$ \\
\hline $\mathrm{DPPH}$ & [17-20] & 11,177 & $\begin{array}{c}\text { 35,136 (“DPPH antioxidant" or "DPPH } \\
\text { antiradical" or "DPPH radical scavenging") } \\
\text { since } 1955\end{array}$ \\
\hline FRAP & [21-23] & 11,040 & $\begin{array}{c}9492(\text { "FRAP" or "Ferric reducing antioxidant } \\
\text { power") }{ }^{3} \text { since } 1994\end{array}$ \\
\hline Folin-Ciocalteu & [24-27] & 7630 & 2803 ("Folin-Ciocalteu antioxidant") since 1976 \\
\hline ORAC & [28-33] & 3478 & $\begin{array}{c}3619 \text { ("ORAC" or “Oxygen radical absorbance } \\
\text { capacity") since } 1993\end{array}$ \\
\hline CUPRAC & [34-36] & 1260 & $\begin{array}{l}685 \text { ("CUPRAC" or "Cupric ion reducing } \\
\text { antioxidant capacity") since } 2004\end{array}$ \\
\hline
\end{tabular}

\footnotetext{
${ }^{1}$ From publication date to the end of 2018. ${ }^{2}$ Possibly overestimated due to widespread usage of TEAC abbreviation for AOA/AOC results expression in different assays. ${ }^{3}$ Words "rapamycin", "photobleaching", and "phosphatase" were excluded from this search to prevent overestimation due to other FRAP abbreviations not related to antioxidant activity assessment (i.e., fujimycin binding protein (FKBP)-rapamycin-associated protein, fluorescence recovery after photobleaching, and fluoride-resistant acid phosphatase).
}

The downsides of these assays have been thoroughly and constantly discussed in the literature; nevertheless, they are rather cheap, experimentally and instrumentally easy to apply, and they give fast, reproducible data. As a result, these methods are widespread, and thus researchers have an opportunity to compare their own findings with others for the same assay. We analyzed citing data based on the Scopus information source, which is a very large abstract and citation database of peer-reviewed literature. Citation index data and frequency of abbreviation use are shown in Table 1. Figure 1a gives insight into the overall picture of the method popularity and abundance considering the above-mentioned reservations. Out of the many modifications of ABTS-based assays, the ABTS/PP is the most popular, for instance, in 2018, ABTS/PP was used in approximately $80 \%$ of all ABTS-based assays citation metrics (Figure 1b). 


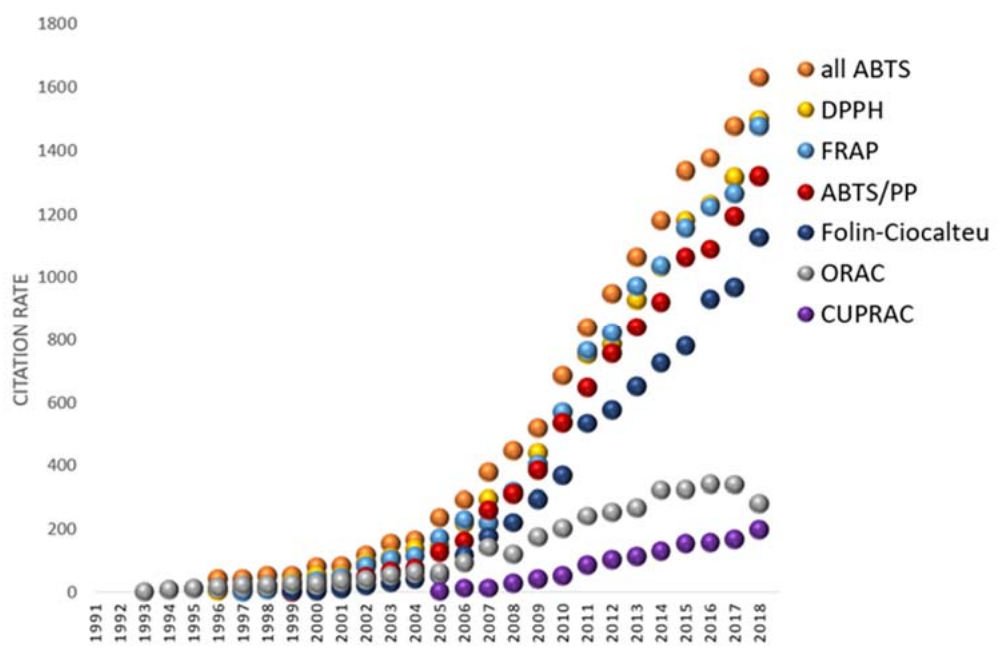

(a)

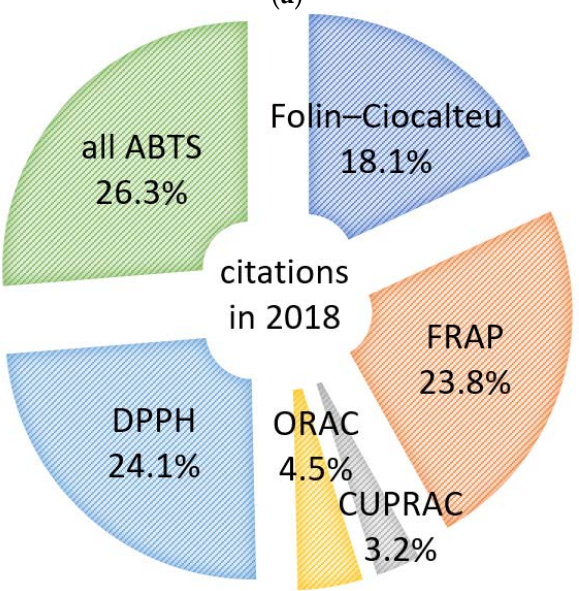

(b)

Figure 1. Citation rates of basic publications of the most widely used AOA/AOC methods from Table 1: (a) Dynamics of citation rates change by year. All methods showed a gradual increase of citations up to 2018, except for the oxygen radical absorbance capacity (ORAC) assays, whose citation number decreased in 2018 to the level of 2013. (b) Distribution of basic publications citations in 2018; the sum of these citations (6212 cites) was taken as $100 \%$. Data are from the Scopus database.

Even though the data in Table 1 are based only on the Scopus citation index and apparently give biased data on method usage frequency due to many reasons, the high citation numbers give an opportunity to overview the general tendency.

\section{ABTS/PP Basic Chemistry}

The basis of the ABTS/PP assay is the interaction between an antioxidant and the pre-generated $\mathrm{ABTS}^{\bullet+}$ radical cation. ABTS ${ }^{\bullet+}$ scavenging can be easily quantitatively detected due to the bleaching of absorption spectrum characteristic maxima at 414, 417, 645, 734, and $815 \mathrm{~nm}$ (Figure 2a). The usually applied characteristic maxima to monitor are 414-417 nm and 730-734 nm (Table 2); however, the latter is the recommended range due to the possible interference of many samples, which can be expected at lower wavelengths, resulting in the underestimated antioxidant capacity [37]. It is important to consider that $\mathrm{ABTS}^{\bullet+}$ absorbance maximum bands shift a little in different solvents due to the solvatochromic effect: methanol $(744-745 \mathrm{~nm})$, ethanol $(753 \mathrm{~nm})$, and propanol-1 $(757 \mathrm{~nm})[38,39]$. The pH impacts the $\lambda_{\max }$ either, for example, in $0.1 \mathrm{M}$ acetate buffer $\mathrm{pH} 5$ a hypsochromic shift is observed with a maximum at $728 \mathrm{~nm}$ [40]. The commonly used end-points for $\mathrm{ABTS}^{\bullet+}$ loss detection are 4 or 6 min. Usually, $\mathrm{ABTS}^{\bullet+}$ is pre-generated a day before, by mixing the PP and ABTS to stand overnight 
(for 12-16 h) -PP stoichiometrically oxidizes ABTS (ABTS/PP ratio 2:1, Figure 2b) to form ABTS ${ }^{\bullet+}$, which can be easily observed by a color change from almost colorless to deep bluish-green. The ABTS to $\mathrm{ABTS}^{\bullet+}$ conversion degree under these conditions is approximately $60 \%$.

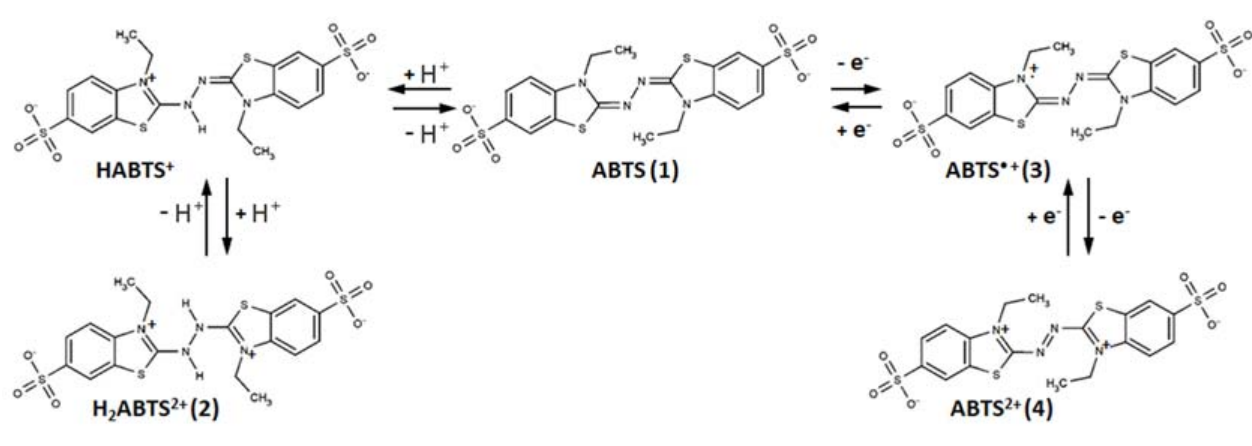

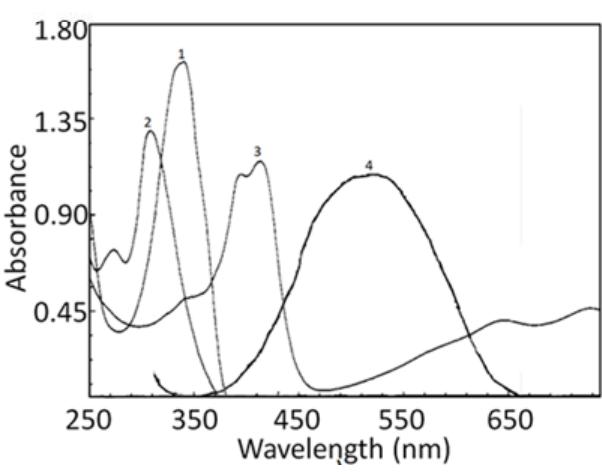

(a)

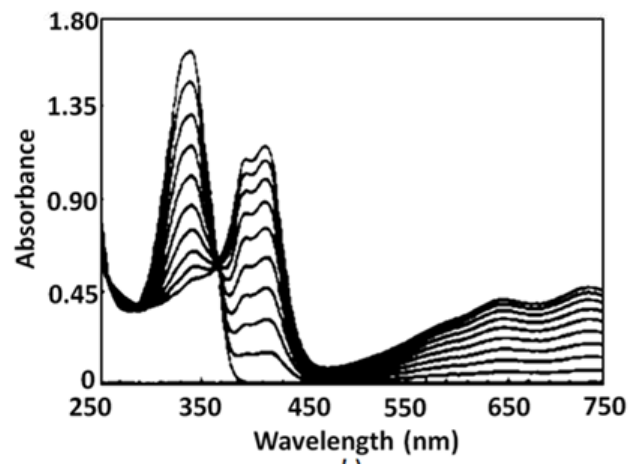

(b)

Figure 2. Structures of ABTS, the protonated and oxidized forms, and their absorption spectra in water: (a) ABTS pH 7 (1), ABTS pH 1 (2), $\mathrm{ABTS}^{\bullet+}$ radical cation (3), and $\mathrm{ABTS}^{2+}$ dication (4); (b) the kinetics of ABTS to $\mathrm{ABTS}^{\bullet+}$ conversion with a radical initiator. Spectra are adopted from Venkatasubramanian et al. (1989) and Scott et al. (1993) [41,42]. Copyright 1994, reproduced with permission from John Wiley and Sons, and copyright 1993, reproduced with permission from the American Chemical Society, respectively.

Table 2. The comparison of $\mathrm{ABTS}^{\bullet+} \mathrm{UV}-\mathrm{VIS}$ spectra characteristics.

\begin{tabular}{ccc}
\hline $\boldsymbol{\lambda}\left(\right.$ ABTS $\left.^{\bullet+}\right), \mathbf{n m}$ & Extinction Coefficient, $\varepsilon$ & Reference \\
\hline $415 \mathrm{~nm}$ & $36,000 \mathrm{~L} \cdot \mathrm{mol}^{-1} \cdot \mathrm{cm}^{-1}$ in water & {$[43,44]$} \\
$414 \mathrm{~nm}$ & $31,1001 \mathrm{~mol}^{-1} \mathrm{~cm}^{-1}$ in water $($ sodium phosphate buffer, $\mathrm{pH} 7.5)$ & {$[3,45]$} \\
& $33,630 \mathrm{~L} \cdot \mathrm{mol}^{-1} \cdot \mathrm{cm}^{-1}$ in ethanol & \\
$734 \mathrm{~nm}$ & $15,000 \mathrm{~L} \cdot \mathrm{mol}^{-1} \cdot \mathrm{cm}^{-1}$ in water & {$[1]$} \\
& $16,000 \mathrm{~L} \cdot \mathrm{mol}^{-1} \cdot \mathrm{cm}^{-1}$ in ethanol & \\
$730 \mathrm{~nm}$ & $12,9471 \mathrm{~mol}^{-1} \mathrm{~cm}^{-1}$ in water $\left(\mathrm{sodium}_{\text {phosphate buffer, } \mathrm{pH} 7.5)}\right.$ & {$[3,45]$} \\
\hline
\end{tabular}

According to the absorption spectrum (see Figure 2a), ABTS is expected to be colorless; however, the ABTS substance is usually pale greenish. This is apparently due to trace amounts of ABTS impurities. This can be indirectly evidenced by the fact that after there is a dissolution of native ABTS in water, the received pale greenish solution immediately becomes colorless after the addition of ascorbate or any other antioxidant compound.

The formation of $\mathrm{ABTS}^{\bullet+}$ apparently occurs according to the mechanism below and corresponds to a simple bimolecular reaction having a low activation energy of approximately $8 \mathrm{kcal} / \mathrm{mol}[41,46]$ :

$$
\mathrm{ABTS}+\mathrm{S}_{2} \mathrm{O}_{8}{ }^{2-} \rightarrow \mathrm{ABTS}^{\bullet+}+\mathrm{SO}_{4}^{\bullet-}+\mathrm{SO}_{4}{ }^{2-}
$$




$$
\mathrm{ABTS}+\mathrm{SO}_{4}{ }^{\bullet-} \rightarrow \mathrm{ABTS}^{\bullet+}+\mathrm{SO}_{4}{ }^{2-}
$$

The variation of $\mathrm{pH}$ in the range 2.0-10.5 does not affect the reaction of ABTS oxidation by PP. In the acidic medium (at a $\mathrm{pH}$ less than 2.0) the reaction rate decreases presumably due to the less reactive protonated forms of ABTS (see Figure 2a) [41].

The $\mathrm{ABTS}^{\bullet+}$ radical cation can undergo further oxidation to form the dication $\mathrm{ABTS}^{2+}$ with $\lambda_{\max }$ at 513-520 nm, $\varepsilon 36000 \mathrm{~L} \mathrm{~mol}^{-1} \mathrm{~cm}^{-1}$ (see Figure 2a) [42]). The $\mathrm{ABTS}^{2+}$ formation kinetics from ABTS $^{\bullet+}$, when an excess of $\mathrm{S}_{2} \mathrm{O}_{8}{ }^{2-}$ is applied, is approximately three times slower than the radical cation $\mathrm{ABTS}^{\bullet+}$ formation from ABTS $[47,48]$. Apparently, the $\mathrm{ABTS}^{2+}$ dication does not influence $\mathrm{ABTS} / \mathrm{PP}$ assay measurements as it has rather low solubility in water and is relatively stable only in the excess of $\mathrm{S}_{2} \mathrm{O}_{8}{ }^{2-}$ anions or in a very acidic medium, with any aqueous dilution resulting in a shift of the reaction balance back to $\mathrm{ABTS}^{\bullet+}[41,47-51]$.

Generally speaking, both "cation" and "dication" terms for compounds 3 and $\mathbf{4}$ are questionable as the total charge implies that they are an anion and neutral compound, as well as a dianion for ABTS itself (1). However, taking into account the fact that the basic work on the "improved ABTS assay" authored by Re et al. uses the "radical cation" term, and, as a consequence, that almost all authors who apply ABTS assay use this "radical cation" term, we also use it in this review.

The $\mathrm{ABTS}^{\bullet+}$ is rather stable and can be used even if not prepared the night before, but one should take into account that in storage, the $\mathrm{ABTS}^{\bullet+}$ gradually decomposes, and thus appropriate blanks should be recorded before each measurement; however, the decomposition rate sufficiently decreases provided that storage temperature is kept below $5{ }^{\circ} \mathrm{C}[3,45,46,52]$. As ABTS ${ }^{\bullet+}$ partly turns back to ABTS, which is evidenced by the absorbance increase at $340 \mathrm{~nm}$, the $\mathrm{ABTS}^{\bullet+} / \mathrm{ABTS}^{\mathrm{a}}$ ratio changes, which can sometimes affect the measured antioxidant capacity [53-56].

\section{Reaction Stoichiometry}

$\mathrm{ABTS}^{\bullet+}$ is a non-natural metastable radical, and there is general controversy of the translation of the results of simple colourimetric antioxidant assays with a physiological context, as well as the ignorance of the rate of radical trapping by antioxidants, which must necessarily be taken into account along with antioxidant capacity to reflect the true antioxidant reactivity. Another drawback of the $\mathrm{ABTS}^{\bullet+}$ model is its difficult to predict chemistry. The latter leads to the complicated kinetic patterns, elevated stoichiometries, and consequent ambiguity of results and their interpretation. One of the most serious shortcomings of ABTS-based methods is that, even for some standard antioxidants such as quercetin, naringin, or glutathione, different TEAC values can be observed between laboratories. The main two reasons are the dependence of the relative antioxidant capacity (e.g., TEAC index) on the concentration for some antioxidants [52,57-59] and the incompleteness of ABTS ${ }^{\bullet+}$ scavenging reaction by 6 th and even more so by the 4 th minute; moreover, by the 30 th min some antioxidants still demonstrate gradual $\mathrm{ABTS}^{\bullet+}$ inhibition [56,60-65].

For this reason, even if one measures $\mathrm{ABTS}^{\bullet+}$ scavenging in the $20-60 \%$ range, the obtained results are going to differ from the same samples measured in the $30-70 \%$ range or taken as $\mathrm{IC}_{50}$. Therefore, results measured at the fourth min vary from those at the sixth min or later, and a quite common picture is the lifted curve of the $\Delta A_{A B T S}{ }^{++}=k C_{\text {antioxidant }}+b$ equation at a small concentration area with a relatively high $b$ coefficient, far from being equal to zero. One of the reasons for such behavior can be attributed to the critical role of the steric accessibility to the $\mathrm{ABTS}^{\bullet+}$ radical site [57]; another is the occurrence of sideline reactions such as coupling adduct formation and their own ABTS $^{\bullet+}$ radical scavenging reactivity.

The stoichiometry of the process is another serious concern. The glutathione (GSH) was found to give higher scavenging stoichiometry with $\mathrm{ABTS}^{\bullet+}$ than the expected 1-eoxidation, which was possibly due to the deeper GSH oxidation to sulphenic and sulphinic acids rather than only to glutathione disulfide glutathione disulfide (GSSG) $[58,66]$. This was evidenced by the fact that oxidized glutathione GSSG also showed the ability to slowly decolorize $\mathrm{ABTS}^{\bullet+}$, apparently due to the further oxidation of sulfur $[60,67,68]$. Another illustration is the number of ABTS $^{\bullet+}$ scavenged after $10 \mathrm{~min}$ 
of incubation, which was about 5.0 for tryptophan or 4.0 for tertbutylphenol; stoichiometric factors are difficult to reason and provoke doubts on the validity of $\mathrm{ABTS}^{\bullet+}$ for the antioxidant capacity determination [46]. The number of phenolic hydroxyl groups generally correlated with the ABTS ${ }^{\bullet+}$ scavenging capacity $[69,70]$; however, some results are out of this line (Figure 3 ).

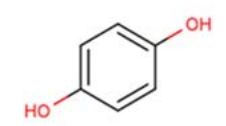

hydroquinone 0.68

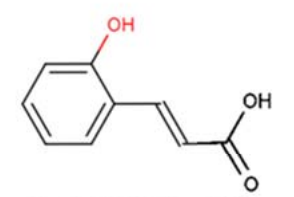

o-coumaric acid

1.05

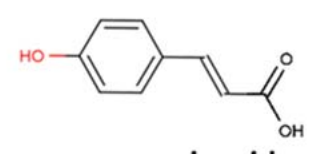

p-coumaric acid

2.00

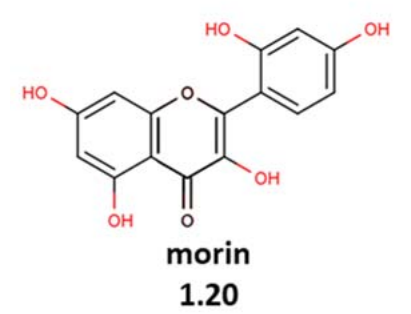<smiles>Oc1ccccc1O</smiles>

catechol 0.97<smiles>Oc1cccc(O)c1</smiles>

resorcinol

1.14<smiles>O=C(O)/C=C/c1ccc(O)c(O)c1</smiles>

caffeic acid

1.01

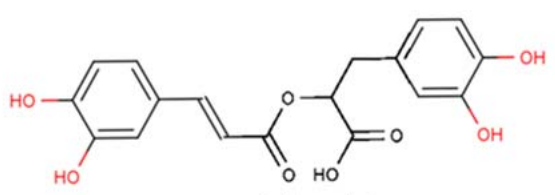

rosmarinic acid

2.13

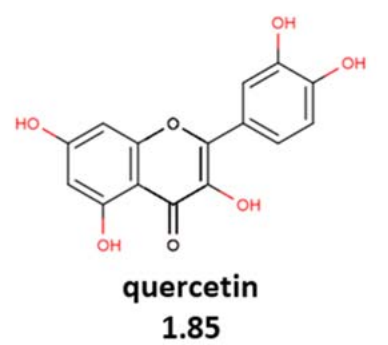

Figure 3. The number of hydroxyls does not always correlate with the TEAC value in ABTS/PP assay [71]. Hydroquinone, catechol, and resorcinol have the same number of hydroxyl groups, but there is a sufficient difference in the TEAC value, as well as in case of morin and quercetin. However, p-coumaric acid and rosmarinic acid showed the same TEAC-value, as well as o-coumaric acid and caffeic acid, in spite of twofold and fourfold differences in the number of hydroxyl groups, respectively. The TEAC values in ethanol are given under the name of each compound.

For instance, $p$-coumaric (one phenolic $\mathrm{OH}$ group) acid was almost equally active to rosmarinic acid (four $\mathrm{OHs}$ ), and $o$ - and $m$-coumaric and isoferulic acids (one $\mathrm{OH}$ each) were almost equal in activity to caffeic acid (two OHs); resorcinol and phloroglucin, which have meta-substitution pattern of $\mathrm{OH}$-groups, were more active than catechol and hydroquinone, having ortho- and paradihydroxy substitutions, respectively [1,71]. Moreover, the stoichiometry for flavonoids is peculiarly high, for example, the quercetin/ABTS ${ }^{\bullet+}$ ratio observed was 1:12, and morin, whose only difference from quercetin is the position of one hydroxyl in the B-ring ( $2^{\prime}$ in morin instead of $3^{\prime}$ in quercetin), showed almost twice the stoichiometry (Figure 3 and Table 3). There are many more examples that are out of the scope of this review; however, all of them witness the difficulty of predicting the chemistry of the ABTS/PP assay. 
Table 3. The comparison of the number of $\mathrm{ABTS}^{\bullet+}$ molecules reduced by one molecule of antioxidant in decolorization and lag-time assays.

\begin{tabular}{|c|c|c|c|}
\hline \multicolumn{2}{|c|}{ Antioxidant } & \multicolumn{2}{|c|}{$\begin{array}{l}\text { The Calculated Number of ABTS }{ }^{\bullet+} \text { Molecules } \\
\text { Reduced by One Molecule of Antioxidant }{ }^{1}\end{array}$} \\
\hline Name & Formula & Decolorization Assay & Lag-Time Assay \\
\hline Trolox & & 2.4 & 1.7 \\
\hline Quercetin & & 12.0 & 4.7 \\
\hline Morin & & 6.9 & 3.3 \\
\hline Rutin & & 6.6 & 2.8 \\
\hline Taxifolin & & 5.9 & 2.7 \\
\hline Apigenin & & 5.3 & ND \\
\hline Naringenin & & 4.6 & ND \\
\hline Glutathione & & 2.7 & 0.8 \\
\hline$\alpha$-Tocopherol & & 1.9 & 1.9 \\
\hline
\end{tabular}

1 The calculated data from [58], considering $\mathrm{ABTS}^{\bullet+}$ radical cation $\lambda_{\max } 734, \varepsilon 15,000 \mathrm{~L} \mathrm{~mol}^{-1} \mathrm{~cm}^{-1}$, and antioxidant concentrations that cause $50 \%$ inhibition or 15 min lag-time of the ABTS ${ }^{\bullet+}$.

To get more insight into the chemistry of $\mathrm{ABTS}^{\bullet+}$ scavenging, it is essential to consider the system modelled (Table 4). In the case of the ABTS/PP decolorization assay, there were three major components in the reaction medium: pre-generated $\mathrm{ABTS}^{\bullet+}$, antioxidant, and the non-reacted and reduced form 
after interaction with antioxidant $\mathrm{ABTS}$. The $\mathrm{ABTS}^{\bullet+}$ concentration, as well as the ABTS concentration (around 47 and $31 \mu \mathrm{mol} / \mathrm{L}$, respectively), was sufficiently higher than the antioxidant concentration (see Table 4). For instance, to inhibit $50 \%$ of $\mathrm{ABTS}^{\bullet+}$, even in the case of such a rather weak antioxidant as Trolox (around $\mathrm{IC}_{50} 11 \mu \mathrm{mol} / \mathrm{L}$ ), the Trolox/ABTS ${ }^{\bullet+}$ ratio was approximately 1:4. However, when a strong antioxidant such as quercetin was added to inhibit $50 \%$ of $\mathrm{ABTS}^{\bullet+}$, its concentration around $2 \mu \mathrm{mol} / \mathrm{L}$ was 25 -fold less than that of $\mathrm{ABTS}^{\bullet+}$.

Table 4. Reagent concentrations in an ABTS/PP decolorization assay ${ }^{1}$.

\begin{tabular}{ccc}
\hline Antioxidant & $\begin{array}{c}\text { Antioxidant Concentration Needed to Inhibit } \\
\mathbf{5 0 \%} \text { of ABTS } \mathbf{A B}^{\bullet+} \boldsymbol{\mu M}\end{array}$ & The Ratio Antioxidant/ABTS $\bullet+$ \\
\hline Trolox & 11.0 & $1: 4$ \\
Glutathion & 8.4 & $1: 6$ \\
Taxifolin & 4.1 & $1: 11$ \\
Quercetin & 1.8 & $1: 26$ \\
$\alpha$-Tocopherol & 12.4 & $1: 4$ \\
\hline
\end{tabular}

1. Data from [58], the inhibited $\mathrm{ABTS}^{\bullet+}$ radical cation concentration was calculated considering $\lambda_{\max } 734, \varepsilon$ $15,000 \mathrm{~L} \mathrm{~mol}^{-1} \mathrm{~cm}^{-1}$; the ratio antioxidant/ABTS ${ }^{\bullet+}$ was calculated considering the initial concentration of ABTS ${ }^{\bullet+}$ before antioxidant addition around $47 \mu \mathrm{M}$; the concentration of ABTS was around $31 \mu \mathrm{M}$; there was supposed to be no $\mathrm{K}_{2} \mathrm{~S}_{2} \mathrm{O}_{8}$.

The consequence of this considerable excess of $\mathrm{ABTS}^{\bullet+}$ was that the total equilibrium of the $\mathrm{ABTS}^{\bullet+}$ scavenging reaction shifted to the right as much as possible, pushing the antioxidant to show maximum reactivity. All intermediates or covalent adducts that have their own AOA were also likely to react with the $\mathrm{ABTS}^{\bullet+}$ radical giving such high stoichiometric coefficients (see Table 3). It is likely that this excess of $\mathrm{ABTS}^{\bullet+}$, as well as the relatively high rates of $\mathrm{ABTS}^{\bullet+}$ consumption in sideline reactions, are among the reasons for the high stoichiometry. For example, the same ABTS/PP system gave much more adequate stoichiometric coefficients when $\mathrm{ABTS}^{\bullet+}$ was generated in situ in the presence of antioxidants in a lag-time assay [58]. In this variant, the solution simultaneously contained antioxidant, potassium persulfate, and the excess of reduced/unreacted ABTS.

As for the $\mathrm{ABTS}^{\bullet+}$ radicals, the main difference of the lag-time assay from the decolorization assay was that their concentration during the lag-time was close to zero due to the capture of the generated radical cations by antioxidants, and it began to grow only after the consumption of most of the antioxidant. Finally, there was no great excess of $\mathrm{ABTS}^{\bullet+}$ and, as a result, the stoichiometries for most antioxidants were close to the real-life reasonable ranges. For example, glutathione in the decolorization assay scavenged approximately three molecules of $\mathrm{ABTS}^{\bullet+}$, whereas the lag-time assay gave a physiologically plausible stoichiometric factor close to 1 (see Table 3). Apparently, due to the gradual inflow of $\mathrm{ABTS}^{\bullet+}$, only the fastest reaction prevailed, that is, $\mathrm{ABTS}^{\bullet+}$ scavenging, and not the coupling or adducts formation and these products' consequent self-scavenging of ABTS ${ }^{\bullet+}$.

At the same time, naringenin and apigenin did not give any classical initial lag-time at all-ABTS ${ }^{\bullet+}$ accumulation in their presence showed different kinetics, demonstrating no initial lag-time, but a kind of delayed lag-time. Finally, morin scavenged $\mathrm{ABTS}^{\bullet+}$ in an easily distinguishable two-stage manner, giving both the initial and delayed lag-time [58].

These kinetic patterns together with the biphasic or more complicated kinetics revealed in other reports [57,60,72-74] prove the fact that not only the parent antioxidant but also its intermediates do scavenge $\mathrm{ABTS}^{\bullet+}$ radicals, contributing to the overall antioxidant capacity. Moreover, it appears that intermediates can demonstrate even higher kinetic rates, as it is outlined for naringenin or apigenin and greater antioxidant capacity. Arts et al. performed elucidation of reagents and product concentration dynamic changes for the chrysin or trolox reaction with $\mathrm{ABTS}^{\bullet+}$ by means of high performance liquid chromatography with ultraviolet detection (HPLC-UV) [64]. It was clearly demonstrated that chrysin totally consumed 5.8 molecules of $\mathrm{ABTS}^{\bullet+}$, out of which only $30 \%$ could be attributed to the chrysin self-scavenging activity, and the remaining $70 \%$ were suggested to be scavenged by reaction product(s); furthermore, the reaction rate of the product with $\mathrm{ABTS}^{\bullet+}$ was deduced to considerably exceed that of 
chrysin with $\mathrm{ABTS}^{\bullet+}$. In contrast, Trolox formed a non-reactive reaction product after direct scavenging of about two molecules of ABTS $^{\bullet+}$.

\section{Reaction Pathways with Adducts Formation}

The most common suggestion with concern to $\mathrm{ABTS}^{\bullet+}$ is that an antioxidant reduces it to the parent substrate ABTS.

In contrast, Osman et al. reported that ABTS at least partly degraded as a result of reactions with polyphenols [75]. Two products of $\mathrm{ABTS}^{\bullet+}$ cleavage were formed when incubating with catechin, epicatechin, or phloroglucinol, whereas the formation of the degradation products was negligible in the absence of the polyphenols and no product formation was observed in the absence of the $\mathrm{ABTS}^{\bullet+}$, indicating that the polyphenols themselves were stable under that experimental conditions. These two products were isolated, purified by preparative HPLC, and subsequently characterized with UV-VIS, ${ }^{1} \mathrm{H}$ NMR, analysis of the elemental composition, and mass-spectrometry. Two structures were proposed, namely, 3-ethyl-2-imino-1,3-benzothiazoline-6-sulfonate (5) and 3-ethyl-2-oxo-1,3-benzothiazoline-6-sulfonate (6) (Figure 4).

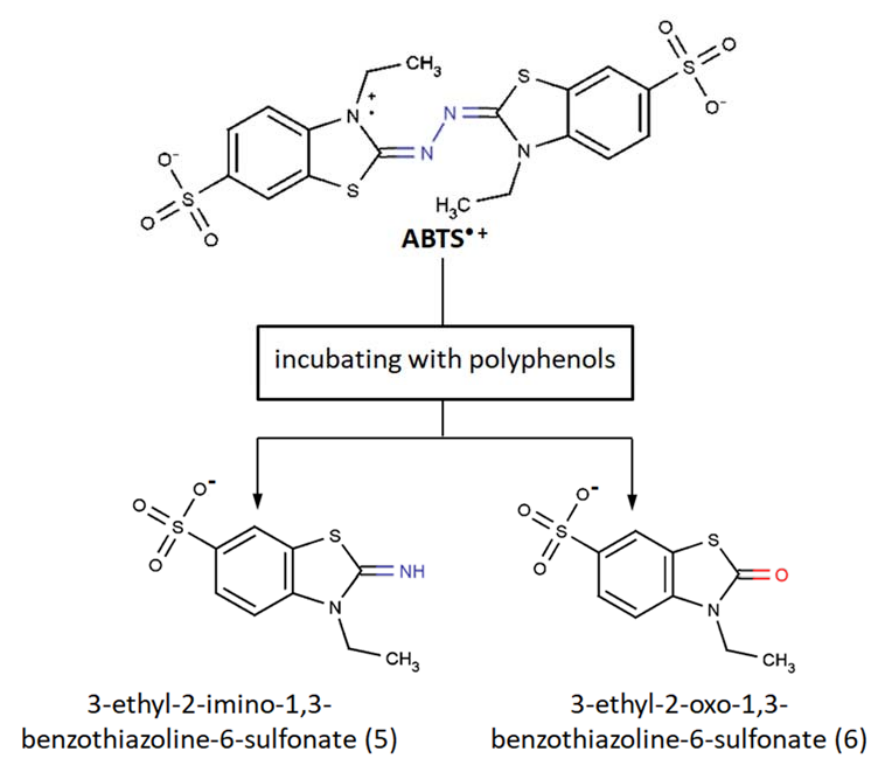

Figure 4. Products of $\mathrm{ABTS}^{\bullet+}$ degradation [75].

Apparently, these products result from oxidative cleavage of the two nitrogen-linked benzothiazole rings. Unfortunately, there is a lack of quantitative estimation of these products' formation except that authors have carefully mentioned that only around $20 \%$ of the original amount of the substrate ABTS was collected. Three additional points should be taken into account with regard to this report:

(1) $\mathrm{As} \mathrm{ABTS}^{\bullet+}$ was generated in the ABTS/laccase system, but not ABTS/PP, one could argue that it could hypothetically influence the observed $\mathrm{ABTS}^{\bullet+}$-antioxidant reaction and subsequent $\mathrm{ABTS}^{\bullet+}$ depletion. There are many precedents when certain antioxidants reveal different antioxidant capacities against the same model radical but a different radical-generating system, for example in the ABTS/metmyoglobin $/ \mathrm{H}_{2} \mathrm{O}_{2}$ assay, the TEAC of quercetin and cyanidin was 4.72 and 4.4 [76,77], whereas in the ABTS/PP assay it was 3.03 and 2.48 [1], respectively. Additionally, laccase can act as an oxidizing agent alone, not to mention that the combination of laccase with ABTS or other mediators shows a higher oxidation ability than laccase or $\mathrm{ABTS}^{\bullet+}$ separately [78-82]. Nevertheless, these concerns seem to be unfounded, as the same researchers observed these $\mathrm{ABTS}^{\bullet+}$ degradation products again in their next report when applying the ABTS/PP system [83].

(2) The time of reaction was $1-2 \mathrm{~h}$, which is much more than the 4-6 min in the original TEAC assay, and thus there was much more time for $\mathrm{ABTS}^{\bullet+}$ cleavage. 
(3) The fact that polyphenol was added "dropwise" to the concentrated ABTS/laccase mixture, which also differs from the original design of ABTS/PP assay, did not seem to matter either, as generally the same situation $\mathrm{C}\left(\mathrm{ABTS}^{\bullet+}\right)>>\mathrm{C}$ (antioxidant) at any given time was reproduced.

Further findings showed that both $\mathrm{ABTS}^{\bullet+}$ degradation products were supposedly not the consequence of self-cleavage, but the result of subsequent adduct formation and further degradation (Figure 5) [83].

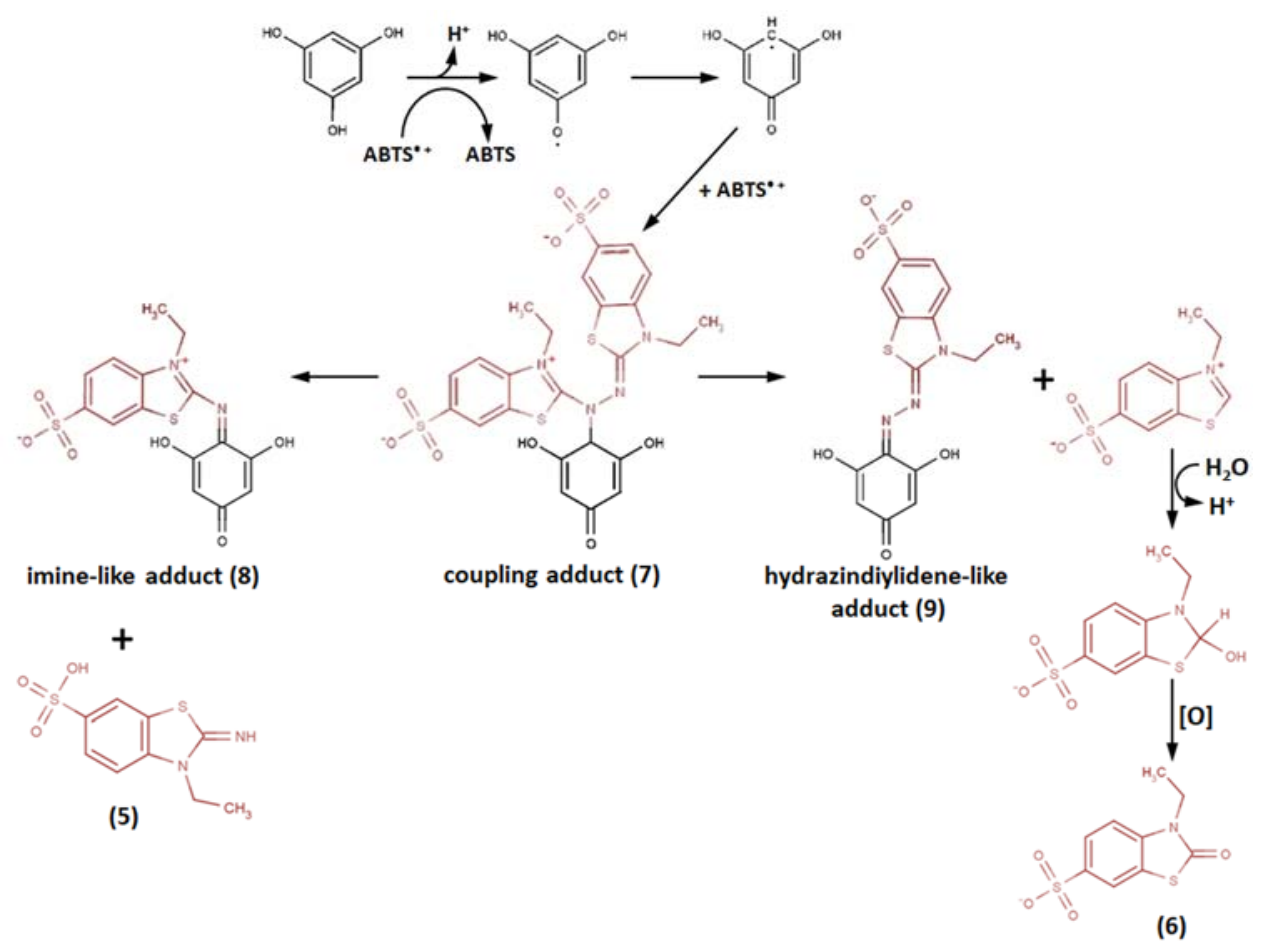

(a)

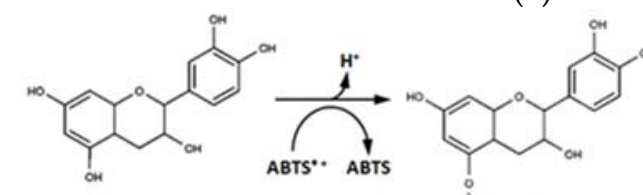

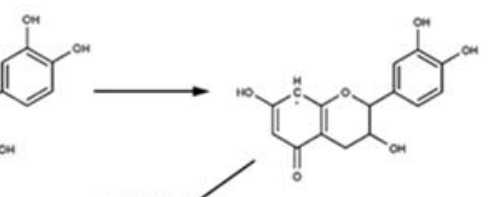
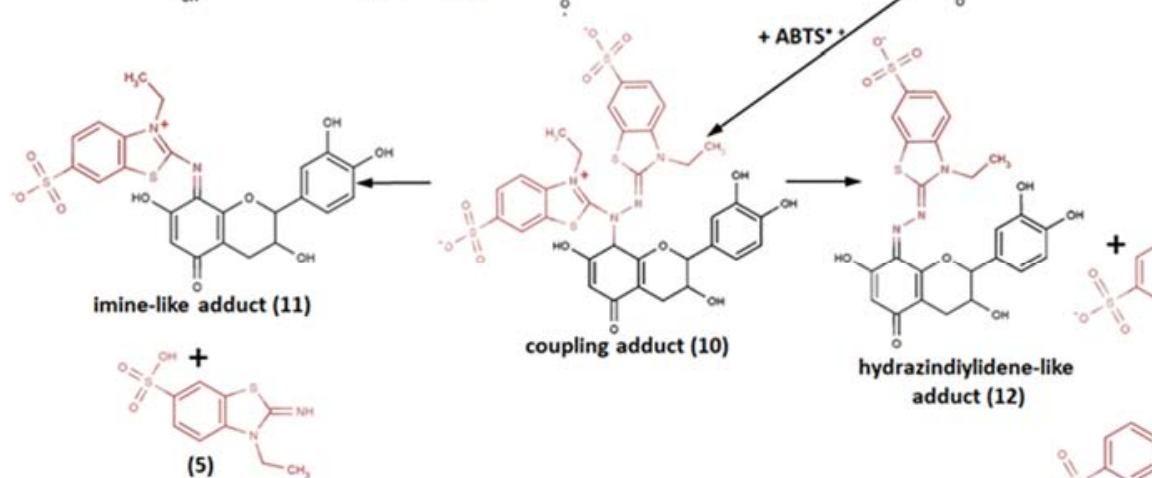

(6)

(b)

Figure 5. Reaction pathways of $\mathrm{ABTS}^{\bullet+}$ with (a) phloroglucinol and (b) catechin [83]. Copyright 2006, adapted with permission from Elsevier. 
Preparative HPLC followed by electrospray ionization mass spectrometry (ESI-MS) analysis of the products of phloroglucinol with $\mathrm{ABTS}^{\bullet+}$ radical cation reaction suggested the formation of two major compounds (Figure 5a): covalent phloroglucinol-ABTS coupling adduct (7) having a $\mathrm{m} / \mathrm{z}$ value of 639.6 (PI) and its hydrazinediylidene-like derivative (9) $\mathrm{m} / \mathrm{z}$ 396.1, as well as the minor imine-like adduct (8) with $\mathrm{m} / \mathrm{z}$ 381.3. Two ions with $\mathrm{m} / \mathrm{z} 259$ and 259.1 assigned to ABTS $^{\bullet+}$ degradation products were detected as well. The two adducts of the catechin/ABTS ${ }^{\bullet+}$ reaction had $\mathrm{m} / \mathrm{z}$ values of 803 and 560 , the coupling reaction product (10) and hydrazinediylidene-like derivative (12), respectively (Figure 5b). Small amounts of the imine-like adduct (11) were also presumably detected on the preparative HPLC chromatogram, but its quantity was not enough for characterization. The $\mathrm{m} / \mathrm{z}$ value difference between two major polyphenol-derived adducts was the same in both cases, amounting to around 243 , which can be attributed to benzothiazolium ion, the predecessor of 3-ethyl-2-oxo-1,3-benzothiazoline-6-sulfonate (6), the second of the previously identified $\mathrm{ABTS}^{\bullet+}$ degradation products, whose formation is, likely, the indirect testimony of hydrazinediylidene-like pathway.

However, as opposed to $\mathrm{ABTS}^{\bullet+}$ degradation products, these proposed structures of $\mathrm{ABTS}^{\bullet+}$ adducts were not rigorously identified, as they were based only on MS/MS analysis. As for phloroglucinol, it is unlikely that other products could be guessed. In the case of catechin, it is disputable that exactly $7-\mathrm{OH}$ was the first to scavenge $\mathrm{ABTS}^{\bullet+}$ and, after that, the coupling underwent through the A-ring. Many structure-activity relationship studies showed much greater importance of the catechol-like B-ring of flavonoids for antioxidant activity manifestation $[1,75,77,84]$ and the kinetic study of free-radical-scavenging action of flavonoids, and catechin in particular indicated that the activities of 5- and 7-OH groups at A-ring were rather weak and even almost negligible, whereas $3^{\prime}$ - and $4^{\prime}-\mathrm{OH}$ groups at B-ring were highly reactive, suggesting that the o-dihydroxyl (catechol) structure in the B-ring is the obvious radical target site for flavonoids as well $[85,86]$. Finally, the examination of catechin, epicatechin, and their metabolites' radical-scavenging potency demonstrated that a free catechol moiety in the B-ring is presumably the most important for the direct antioxidant activity and apparently leads to the formation of epicatechin quinone [87,88].

At the same time, the mechanism involved in $\mathrm{ABTS}^{\bullet+}$ radical cation quenching can also contribute considerably to the domination in various reaction pathways. Several reports discuss possible mechanisms involved in $\mathrm{ABTS}^{\bullet+}$ quenching, suggesting the mixed hydrogen atom transfer/single electron transfer (HAT/SET) reaction mechanism, stepwise electron transfer-proton transfer (ET-PT), and concerted electron-proton transfer (CEP) mechanism with water as the proton acceptor, among others, and apparently any of them can occur in parallel or prevail $[6,9,10,55,62,89-92]$. The millisecond scale reaction rates of $\mathrm{ABTS}^{\bullet+}$ scavenging complicate the discrimination between possible mechanisms involved in $\mathrm{ABTS}^{\bullet+}$ scavenging and the determination of the prevailing mechanism; thus, further fast flow-mix techniques are needed to elucidate the dominant mechanism [57]. Nevertheless, it is important to consider that polyphenols as the routine objects and water (commonly phosphate buffer solution (PBS) pH 7.4) or alcohols as the solvents imply the sequential proton loss electron transfer (SPLET) mechanism as the most probable.

The SPLET mechanism is as follows:

$\mathrm{ROH} \rightarrow \mathrm{RO}^{-}+\mathrm{H}^{+}$(in water or alcohols, where $\mathrm{ROH}$ is, for example, phenolic comound)

$$
\begin{gathered}
\mathrm{RO}^{-}+\mathrm{ABTS}^{\bullet+} \rightarrow \mathrm{RO}^{\bullet}+\mathrm{ABTS} \\
\mathrm{ABTS}+\mathrm{H}^{+} \rightarrow \mathrm{ABTSH}^{+}
\end{gathered}
$$

Due to the partial ionization of phenols in water and alcohols, phenoxide anions, which are known as being much easier and faster to oxidize than corresponding phenols, play their primary role acting as electron donors in the SPLET mechanism [14,93]. This mechanism-proposed independently by Litwinienko et al. and Foti et al. in 2004 [94,95] — seems to be the most favored for the abovementioned conditions $[14,93,96]$. Thus, the relative acidities of hydroxyls in catechin can determine the predominant reaction pathway. 
From one point of view, the resorcinol-like A-ring is presumably slightly more acidic than the catechol-like B-ring due to the electron withdrawing nature of the hydroxyls in resorcinol, and thus the formation of an anion at 7-OH or 5-OH might seem to be preferable. In contrast, some experimental data indicate that in the case of catechin, the B-ring is slightly more acidic, even though competitive deprotonation on B- and A-rings takes place $[97,98]$. The comparative acidity of A- and B-rings can be critical, as flavonoid anions are better electron donors and radical scavengers than corresponding neutral molecules [99-102], whereas electron transfer at deprotonated hydroxyls prevails. Even though the $\mathrm{pH}$ in the reaction medium was 5.0 , and less than $0.1 \%$ of catechin was ionized (taking into account the $\mathrm{pKa}_{1}$ of catechin around 8.7 [103-105]), the kinetic rates of electron transfer are normally much greater than hydrogen atom transfer, and therefore a very low anion concentration can produce a large rate enhancement and dominate [93].

Meanwhile, B-ring ortho-dihydroxyls act as electron-donating groups, decreasing $\mathrm{O}-\mathrm{H}$ bond dissociation enthalpies and, hence, increasing the kinetics for hydrogen transfer $[93,106]$. This splitting makes it difficult to give a robust forecast for the overall effects on the direction of the reaction. Nevertheless, an A-ring adduct seems to be more reasonable according to spectra considerations of authors of this work, together with the observations made in Arnao's group study on ABTS-flavonoid complex formation $[107,108]$, which noted that A-ring complexes give shorter wavelength maxima than B-ring complexes.

Another point to consider is, again, the experiment design. Apart from the incubation time $(2 \mathrm{~h})$, which was again much longer than $4-6$ min in the decolorization assay, the ratio of reagents was far from usual. In contrast to the normally observed $\mathrm{ABTS}^{\bullet+}$ multiple excess in the reaction medium, the catechin/ABTS ${ }^{\bullet+}$ ratio was 1:1; moreover the phloroglucinol concentration was almost 10-fold higher than $\mathrm{ABTS}^{\bullet+}$ during incubation. The first consequence was that there was much more time to form adducts when the $\mathrm{ABTS}^{\bullet+}$ scavenging reaction was possibly completed. The second consequence was that a lag of excess $\mathrm{ABTS}^{\bullet+}$ limits the opportunity for these antioxidants to exhibit all of their antioxidant potential. ABTS-phloroglucinol adducts were tested and demonstrated their own radical scavenging activity against $\mathrm{ABTS}^{\bullet+}$, thus forming further deeper oxidized forms and contributing to the total antioxidant capacity, which confirmed the prediction that chemical reactions following parent compound oxidation are at least partly in charge of their higher radical scavenging capacities $[109,110]$.

To sum up, two points are worth mentioning:

(1) The principal possibility of $\mathrm{ABTS}^{\bullet+}$ degradation and ABTS-antioxidant adduct formation was demonstrated for the first time in the ABTS/PP assay.

(2) The extent to which this degradation and adduct formation influenced the final TEAC was not obvious due to the modified experiment design and no quantitative estimations.

Controversial data were reported on catechin oxidation with the ABTS/laccase system, where no adducts were detected. Instead, dimers, trimers, tetramers, and their oxidized forms were elucidated [111]; this is another consideration in favor of the importance of the experiment design and in particular the $\mathrm{ABTS}^{\bullet+}$-generating system with regard to adduct formation.

In general, the reactions of different phenols with $\mathrm{ABTS}^{\bullet+}$ had been reported far before the discussed Osman et al. report and even the ABTS/PP assay invention itself. Different research groups suggested the coupling reaction between $\mathrm{ABTS}^{\bullet+}$ and phenolics but without their structural elucidation, that is, $\mathrm{ABTS}{ }^{\bullet+}$ (ABTS/horseradish peroxidase $/ \mathrm{H}_{2} \mathrm{O}_{2}$ ) and naringenin were reported to form the coupling product with a maximum absorption at $560 \mathrm{~nm}$, whereas guaiacol and erol, the monomeric lignin model compounds, underwent coupling reactions with ABTS $^{\bullet+}$ (ABTS/laccase) leading to a copolymer, which could undergo deeper coupling with $\mathrm{ABTS}^{\bullet+}$ to an extent that enabled their complete solubilization in water buffer, as well as several others [82,108,112-114]. However, the first report devoted to phenol-ABTS ${ }^{\bullet+}$ coupling reaction products' isolation and structural determination dates to 1986. Matsumura et al. studied laccase-catalyzed oxidation of 3-hydroxybenzoic and 4-hydroxybenzoic acid in the presence of ABTS as a model reaction for laccase activity or hydroxybenzoic acid concentration estimation [115,116]. 
After incubation at $\mathrm{pH}$ 6.0, the two products were isolated via column chromatography and then thoroughly characterized and identified by means of secondary ion mass spectrometry (SIMS), UV-, IR-, ${ }^{1} \mathrm{H}-$, and ${ }^{13} \mathrm{C}-\mathrm{NMR}$ spectroscopy. Both appeared to be relatively stable hydrazinediylidene-like compounds: 6-(6'-sulfo-3'-ethylbenzothiazol-2'-ylidenehydrazono)-3- oxo-1,4-cyclohexadiene-1-carboxylate (13) and 3-(6'-sulfo-3'-ethylbenzothiazol-2'-ylidenehydrazono)-4-oxo-1,5'-cyclohexadiene-1-carboxylate (14) (Figure 6). Again, the differences between ABTS/PP and ABTS/laccase are to be considered, but in general, the same coupling pattern is difficult to argue.

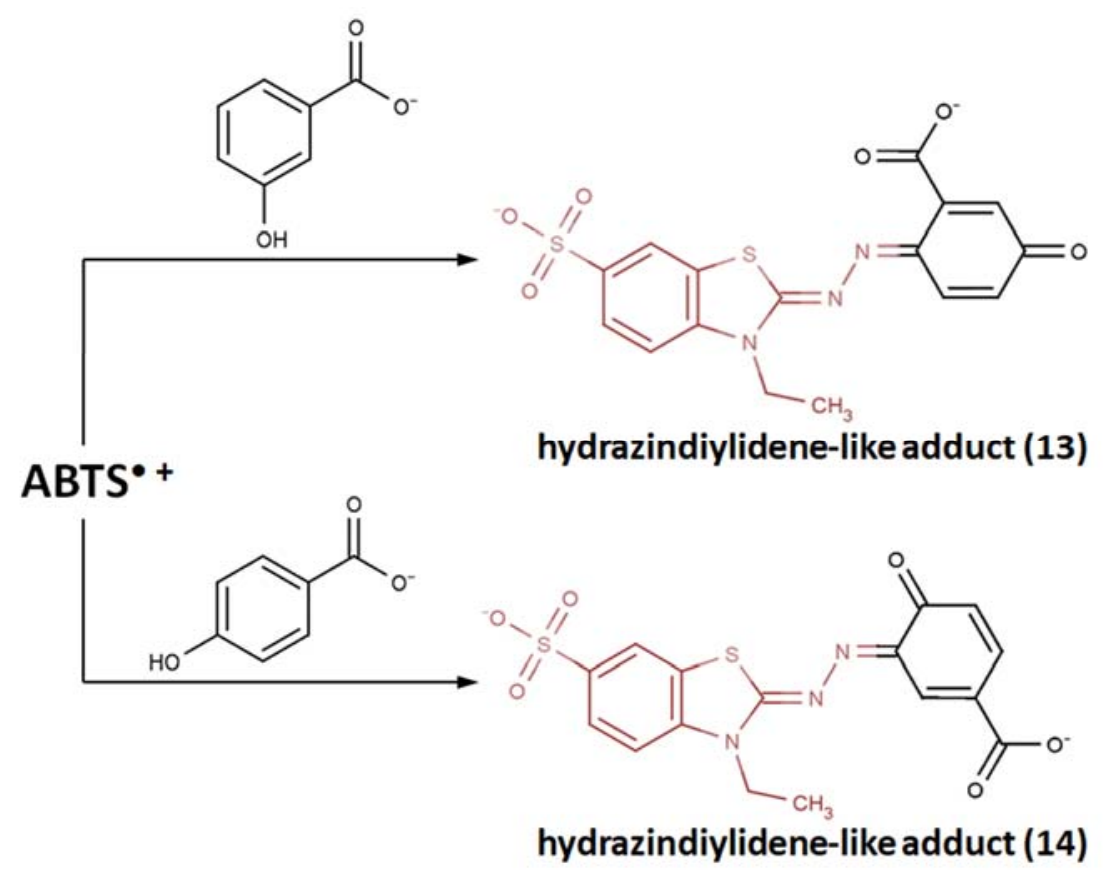

Figure 6. Reaction pathways of $\mathrm{ABTS}^{\bullet+}$ with 3-hydroxybenzoic acid and 4-hydroxybenzoic acid [115].

Copyright 1986, adapted with permission from Taylor and Francis.

Partially consistent results were obtained for adduct formation during the incubation of ABTS ${ }^{\bullet+}$ with quercetin or its glycosides rutin, hyperoside, and quercitrin [117]. In the case of quercetin, two products were detected in the HPLC ESI-MS chromatogram along with ABTS itself. The first one was ascribed to have the potential structure of A-dihydroxy dihydroflavonol pinobanksin with $\mathrm{m} / \mathrm{z} 319$ and 301 in PI mode, which were attributed to $[\mathrm{M}+\mathrm{H}+2 \mathrm{Na}]$ and $\left[\mathrm{M}+\mathrm{H}-\mathrm{H}_{2} \mathrm{O}+2 \mathrm{Na}\right]$, respectively, as well as $\mathrm{m} / \mathrm{z} 317$ [M-H+2Na] in NI mode. Another manifested as a PI ion with m/z 319.0 and 476.3, which was interpreted as the formation of dihydroflavonol-like compound taxifolin with imine-like adduct (15) fragmented by the elimination of ring B and 3-ethyl-2-imino-1,3-benzothiazoline-6-sulfonate (Figure 7).

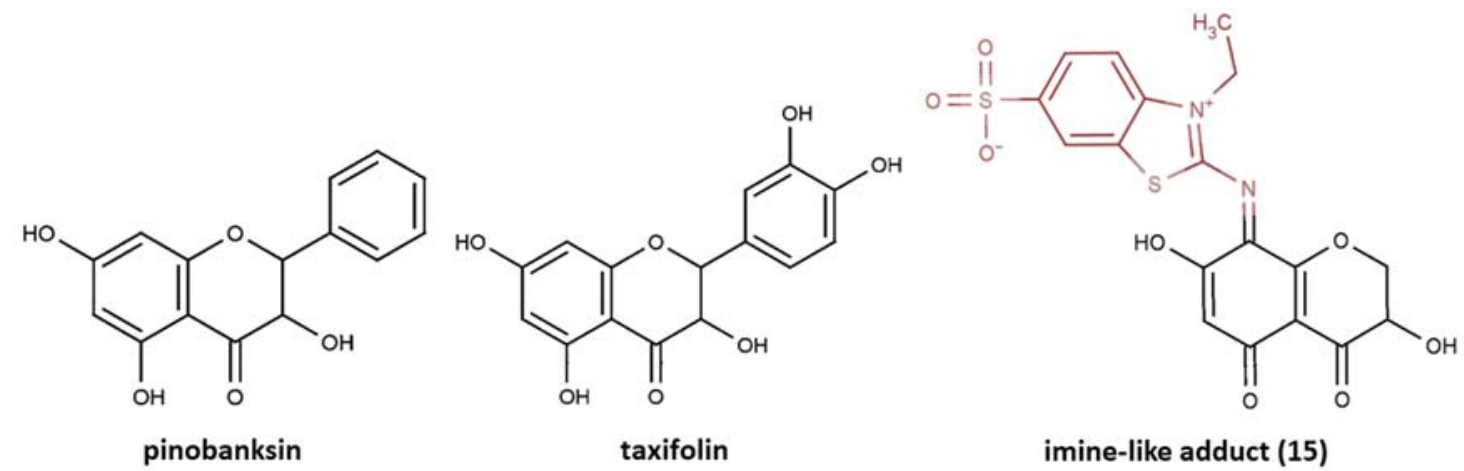

Figure 7. The proposed structures of $\mathrm{ABTS}^{\bullet+}$ with quercetin reaction products [117]. 
Quercetin to pinobanksin and taxifolin conversions need to be evidenced by more rigorous examination, and still leave questions, such as the fact that formation of these products indicates the reduction but not the expected oxidation of quercetin, being far from the previously reported quercetin oxidation products [99,118-124]. For rutin, hyperoside, or quercitrin, the products of coupling with ABTS $^{\bullet+}$ apparently degraded with the loss of the 3-ethyl-2-imino-1,3-benzothiazoline-6-sulfonate fragment to form the imine-like adducts evidenced by the corresponding MS spectra. It is interesting to note that no hydrazinediylidene-like derivatives were revealed in this work. Whether this was due to their absence among the reaction products or whether the absorbance wavelength at $340 \mathrm{~nm}$ (applied for monitoring the HPLC mixtures separation) made their detection difficult, it is unclear. For instance, the previously discussed catechin-ABTS ${ }^{\bullet+}$ and phloroglucinol-ABTS ${ }^{\bullet+}$ major adducts appeared to be hydrazinediylidene-like derivatives, which were demonstrated to have characteristic spectra with maximum at $455 \mathrm{~nm}$ and almost no absorption in the $340 \mathrm{~nm}$ area [83]. Furthermore, the similar absorption spectra were attributed by Arnao's group to 10 ABTS-flavonoid complexes having wavelength maxima between $445 \mathrm{~nm}$ and $613 \mathrm{~nm}$, including quercetin $(445 \mathrm{~nm})$, rutin $(476 \mathrm{~nm})$, and hyperoside $(477 \mathrm{~nm})$ [107], which could make them difficult to be detected at $340 \mathrm{~nm}$. Nevertheless, in the latter work, the authors pointed out that the reaction between $\mathrm{ABTS}^{\bullet+}$ in the presence of horseradish peroxidase $/ \mathrm{H}_{2} \mathrm{O}_{2}$ and flavonoid was different to that which occurred when the pre-generated $\mathrm{ABTS}^{\bullet+}$ was used for antioxidant activity measurement [1,46,125-127]. Indeed, as we have mentioned before, another $\mathrm{ABTS}^{\bullet+}$-generating system, ABTS/laccase, was revealed as a more powerful oxidant than $\mathrm{ABTS}^{\bullet+}$ itself.

To a certain extent, a similar situation was observed for the interaction between propofol (2,6-diisopropylphenol) and $\mathrm{ABTS}^{\bullet+}$ [128], which was studied in conditions reproducing Osman et al. [83] with minor modifications, wherein ABTS/PP was used for ABTS ${ }^{\bullet+}$ production, the propofol/ABTS ${ }^{\bullet+}$ ratio was close to 2:1, and the incubation time was $30 \mathrm{~min}$. Four products were identified by means of HPLC ESI-MS in PI mode with $\mathrm{m} / \mathrm{z}$ 691.5, 679.8, 437.4, and 259.5. The proposed structures (16) and (18) reproduced an imine-like reaction pathway with the reduced imine-like adduct final formation (18) (Figure 8). The proposed (17) structure formation was difficult to reason, however, and any other variant of interpretation is also far from being unambiguous as $\mathrm{m} / \mathrm{z} 679.8$ indicated the loss of only 12 mass units from the basic propofol/ABTS ${ }^{\bullet+}$ coupling product with $\mathrm{m} / \mathrm{z}$ 691.5. As for hydrazinediylidene-like adducts, product (6) indirectly witnessed their formation, but they themselves were not detected. However, in this case, the arguments about the suitability of the chosen wavelength of HPLC-UV detection does not seem reasonable enough $(254 \mathrm{~nm})$.

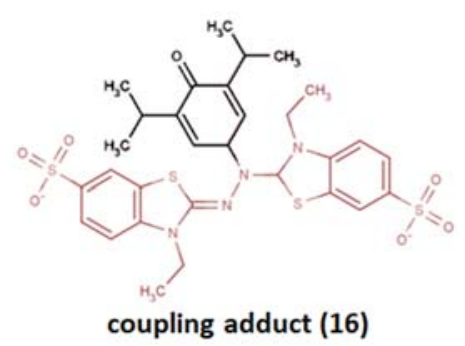

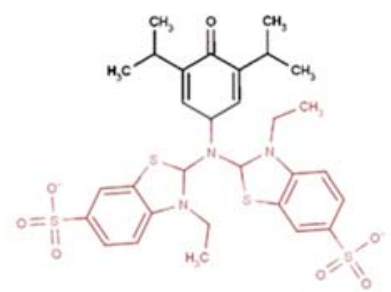

(17)

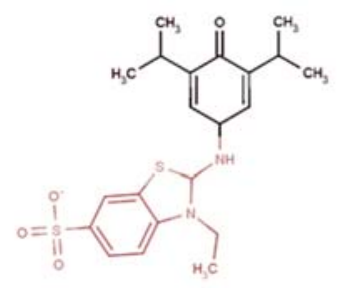

(18)

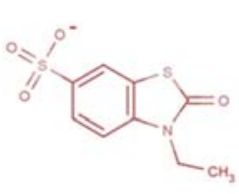

(6)

Figure 8. The proposed structures of $\mathrm{ABTS}^{\bullet+}$ with propofol reaction products [128].

The coupling of $\mathrm{ABTS}^{\bullet+}$ with another monophenol compound, the glucoside of hydroquinone arbutin, was studied by Tai et al. [129]. The formation of a purple-colored adduct was observed for the incubation of arbutin with $\mathrm{ABTS}^{\bullet+}$ at a molar ratio $1: 4(\mathrm{pH}$ 6, room temperature). The reaction products were thoroughly isolated on chromatographic columns and thereafter fully characterized and identified by high resolution electrospray ionization mass spectrometry (ESI-HRMS) and several NMR spectra $\left({ }^{1} \mathrm{H},{ }^{13} \mathrm{C},{ }^{1} \mathrm{H}-{ }^{1} \mathrm{H}\right.$ COSY, heteronuclear single quantum coherence (HSQC), and heteronuclear multiple bond correlation (HMBC)). 
Here, hydrazinediylidene-like adduct (19) was determined to be the major product, as well as 3-ethyl-2-oxo-1,3-benzothiazoline-6-sulfonate (6), whereas no imine-like adducts were detected (Figure 9). The incubation for $15 \mathrm{~min}$ and $120 \mathrm{~min}$ showed almost no difference in reaction products; moreover, the further experiments demonstrated that even $5 \mathrm{~min}$ was enough for the arbutin-ABTS ${ }^{\bullet+}$ degradation fragment adduct formation, thus showing that the standard 6-10 min of incubation in ABTS/PP assay can be quite enough for adduct formation to contribute to the total antioxidant capacity measured. Interestingly, that arbutin-ABTS ${ }^{\bullet+}$ hydrazinediylidene-like adduct (19) revealed no antioxidant activity in contrast to 3-ethyl-2-oxo-1,3-benzothiazoline-6-sulfonate (6), which revealed radical-scavenging activity, though was almost negligible.

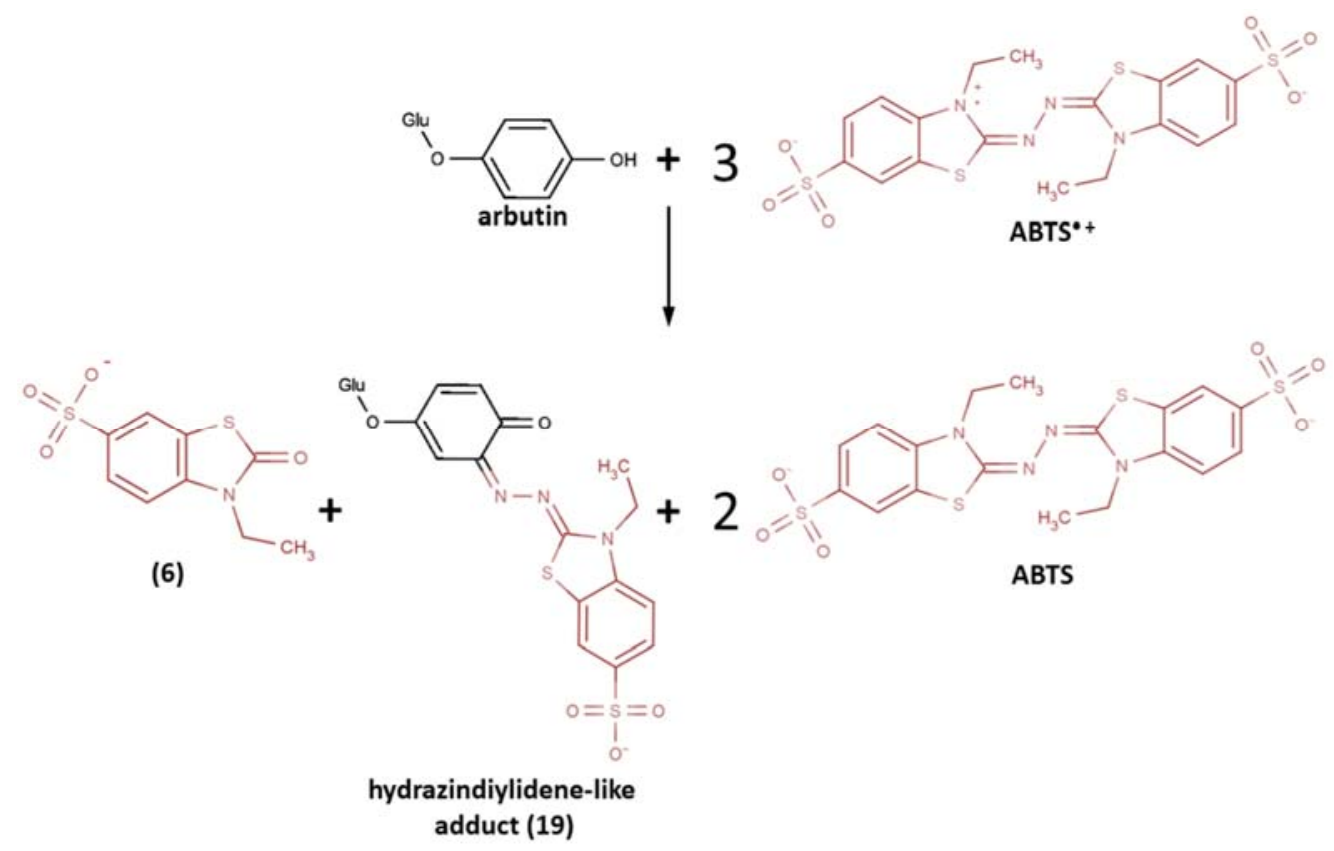

Figure 9. The reaction of $\mathrm{ABTS}^{\bullet+}$ with arbutin [129]. Copyright 2016, adopted with permission from American Chemical Society.

The model compound mimicking the phenolic subunits in lignin, 1-(4-hydroxy-3-methoxyphenyl) -2-(2-methoxyphenoxy) propane-1,3-diol (guaiacylglycerol- $\beta$-guaiacyl ether, GBG), reported by Hilgers at al., was also able to couple with ABTS $^{\bullet+}$ (Figure 10) [130]. This study set out with the aim of assessing the reactivity of different laccase/mediator systems towards phenolic lignin structures. Thus, $\mathrm{ABTS} /$ laccase, laccase alone, and pre-generated $\mathrm{ABTS}^{\bullet+}$ radical cation were applied as oxidants to assess different GBG oxidation pathways. The results partly corroborated the findings of the aforementioned reports-the $\mathrm{ABTS}^{\bullet+}$, obtained in reaction with laccase $\left(\mathrm{pH} 4,40{ }^{\circ} \mathrm{C}\right)$ and then centrifuged over centrifugal filter to get rid of laccase, alone oxidized GBG to finally form the coupling product (20), oxidation products of GBG (GBGox) (22), GBG dimer (23), and oxidized GBG dimer (24), which were detected by employing reversed-phase ultrahigh-performance liquid chromatography with photodiode array and electrospray ionization mass spectrometry detection (RP-UHPLC-PDA-ESI-MS ${ }^{\mathrm{n}}$ ).

Surprisingly, no hydrazindiylidene-like adduct was detected. This could be ascribed to the time factor, as the 2 min incubation described in this report could be too short a time for their formation; however, personal correspondence with the author of this work revealed that 2 min was quite enough, which was confirmed by the disappearance of the green color within a very short time (indicating disappearance of the radical cations). Moreover, the measurement of the reaction mixture after $60 \mathrm{~min}$ gave a chromatogram identical to that of the $2 \mathrm{~min}$ incubation. Regarding the fact that they did not observe a hydrazindiylidene-like adduct in this incubation, in personal communication with the authors via e-mail, Roelant Hilgerssuggested that the reason was that there was too little $\mathrm{ABTS}^{\bullet+}$ formed to further oxidize the coupling product to a hydrazindiylidene-like product; however, 
the incubation time was definitely not the limiting factor. The preliminary experiments performed by the authors of this review showed that indeed different antioxidant/ABTS ${ }^{\bullet+}$ ratios can lead to different products, for instance, morin forms a yellow-colored solution in the excess of antioxidant and a reddish-colored one when the excess of $\mathrm{ABTS}^{\bullet+}$ is applied, which are presumably the coupling adduct and hydrazindiylidene-like adduct, respectively. Similar results were observed for several other flavonoids (data not yet published).

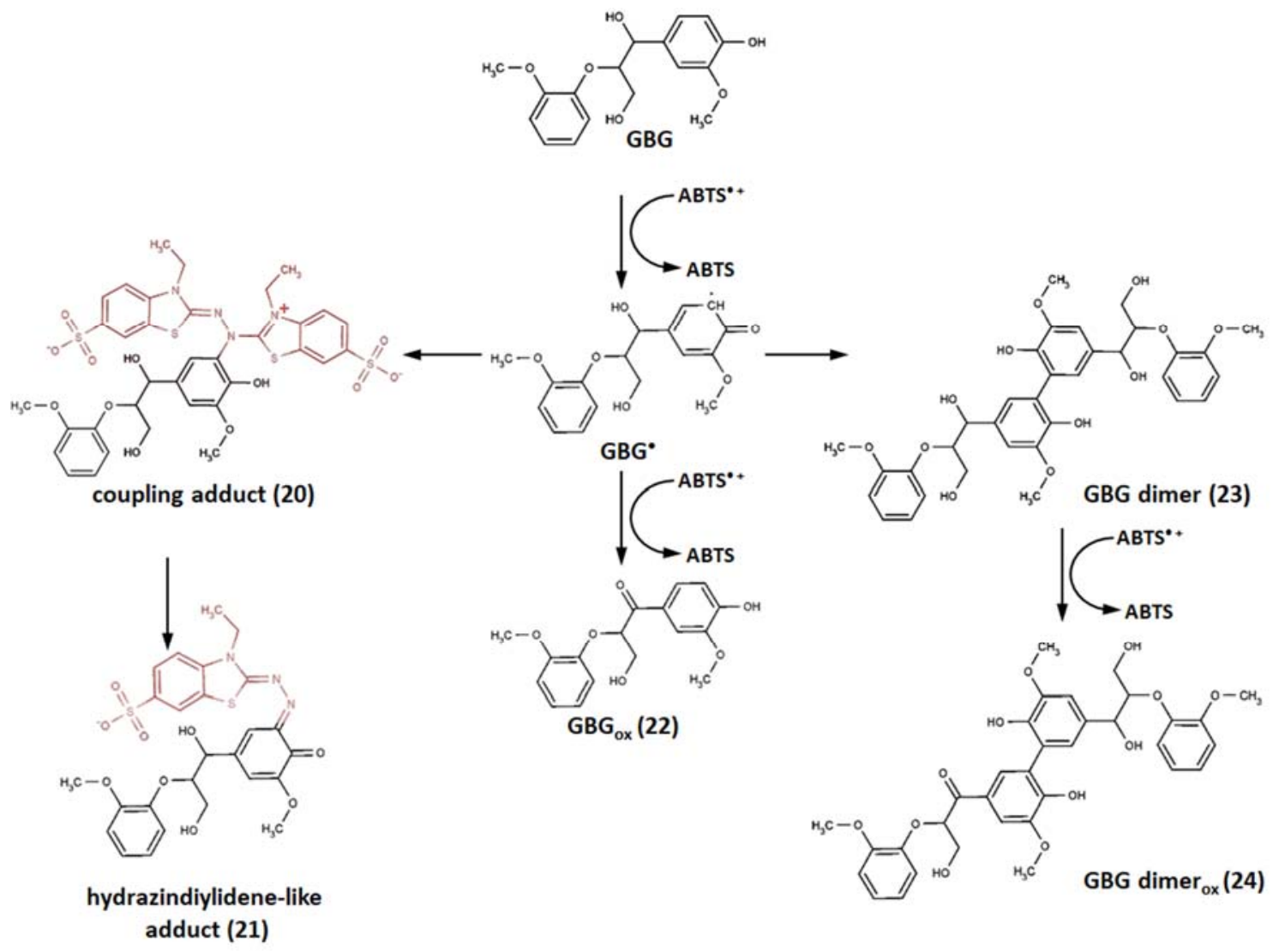

Figure 10. Reaction pathways of $\mathrm{ABTS}^{\bullet+}$ with guaiacylglycerol- $\beta$-guaiacyl ether (GBG) [130]. Copyright 2018, adopted with permission from American Chemical Society.

The pair laccase/ABTS showed higher oxidation power-GBG was oxidized at a higher rate and gave deeper oxidation products. The reactant and product abundance timeline clearly demonstrated that GBG was converted within the first minute of incubation, giving rise to GBGox (22) and GBGox with an ABTS coupling product similar to the GBG-ABTS coupling adduct (21), whose concentrations peaked and then almost totally decreased by the 20th min. The concentration of the hydrazinediylidene-like adduct (21) of ABTS ${ }^{\bullet+}$ and GBG was also the highest after $1 \mathrm{~min}$, but decreased relatively slower and dropped to about a quarter of the initial concentration by the end of the first hour. At the same time, similar to hydrazinediylidene-like adduct of $\mathrm{ABTS}^{\bullet+}$ and GBGox (21), as well as 3-ethyl-2-oxo-1,3-benzothiazoline-6-sulfonate (6), concentrations progressively increased during the first hour. Conclusively, the latter two products appeared to be the ultimate products of oxidation after $24 \mathrm{~h}$.

\section{Reaction Pathways without Adduct Formation}

It is clear that there is not yet enough data to definitively judge the main mechanisms that underlie the reaction of $\mathrm{ABTS}^{\bullet+}$ with the tested compound. In contrast to the studies outlined above that revealed coupling reaction products, there are reports that have characterized $\mathrm{ABTS}^{\bullet+}$-mediated oxidation products, but with no antioxidant-ABTS adducts detected. To illustrate this fact, no adduct 
formation was observed in the $\mathrm{ABTS}^{\bullet+}$-mediated oxidation of doxorubicin, an antineoplastic agent with anthracycline glycoside structure [131]. The oxidation products 3-methoxysalicylic acid (25) and 3-methoxyphthalic acid (26) were identified by quadrupole time of flight mass spectrometry (QTOF-MS) in comparison with authentic standards and are consistent with the literature as the expected result of doxorubicin oxidation (Figure 11) [132-135].

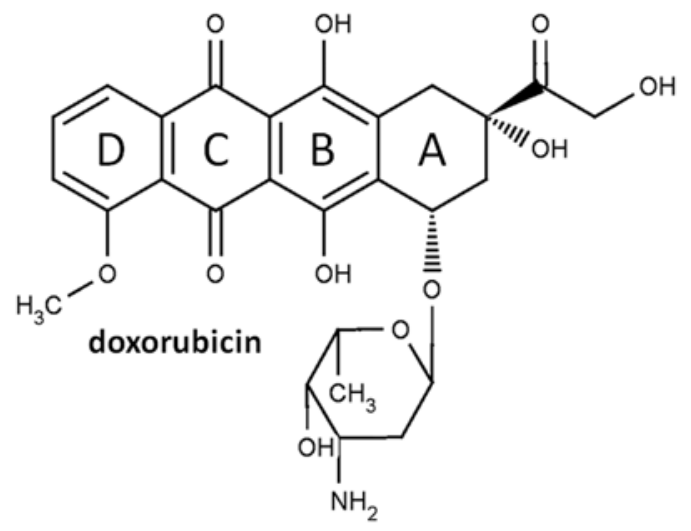<smiles>COc1cccc(C(=O)O)c1O</smiles>

(25)<smiles>COc1cccc(C(=O)O)c1C(=O)O</smiles>

(26)

Figure 11. Doxorubicin and its oxidation products: 3-methoxysalicylic acid (25) and 3-methoxyphthalic acid (26) [131].

The $\mathrm{ABTS}^{\bullet+}$ for doxorubicin oxidation was generated in situ, adding $\mathrm{H}_{2} \mathrm{O}_{2}$ solution to a sample consisting of ABTS and lactoperoxidase in phosphate buffer $\mathrm{pH} 7.0$ giving rise to absorbances measured at 415 and $730 \mathrm{~nm}$. In the presence of doxyrubicin, the same sample demonstrated no ABTS ${ }^{\bullet+}$ formation for a certain period of time (lag-time), during which doxyrubicin depletion to a near zero level could be observed at $480 \mathrm{~nm}$. The oxidation products for MS analysis were collected right after the lag-time when the oxidation of doxyrubicin was nearly completed (absorbance at $480 \mathrm{~nm}$ reached minimum). Generally, these conditions, that is, in situ $\mathrm{ABTS}^{\bullet+}$ generating in the presence of $\mathrm{H}_{2} \mathrm{O}_{2}$, the overall exposition time (10-20 $\mathrm{min}$ ) was found to be similar to the conditions of flavonoid-ABTS ${ }^{\bullet+}$ coupling reported by Arnao's group $[107,108]$ and therefore adduct formation could be expected. However, the bulky structure of doxyrubicin, as well as the absence of appropriate sites of coupling, apparently limits adduct formation. The only probable "free" positions are located in the D-ring, which is unlikely to act in radical scavenging.

The analysis of the products of melatonin oxidation by the pre-generated ABTS ${ }^{\bullet+}(\mathrm{ABTS} / \mathrm{PP})$ was performed by means of high performance liquid chromatography with electrochemical detection (HPLC-ECD) with an external standard (1:1 ratio, incubation time 0.5-12.0 min, $\mathrm{pH} 7.4)$ and thin layer chromatography (TLC; different ratios, incubation time $4 \mathrm{~h}, \mathrm{pH}$ 7.4). Two principal products were revealed: cyclic 3-hydroxymelatonin (c3OHM, 27) and N1-acetyl-N2-formyl-5-methoxykynuramine $\left(\right.$ AFMK, 28) (Figure 12) [136]. At the excess of $\mathrm{ABTS}^{\bullet+}$, the dominant metabolite was AFMK; at the 1:1 ratio, c3OHM formation was threefold more than that of AFMK. Both products had been detected earlier for melatonin oxidation by other oxidants; thus, $\mathrm{ABTS}^{\bullet+}$ again, as in the case of doxorubicin oxidation, gave relevant non-specific oxidation products [137-139]. Further examinations showed both products' own antioxidant activity, as well as the formation of other deeper oxidation products of melatonin $[59,140]$. None of these studies detected any products of coupling with ABTS ${ }^{\bullet+}$.

The oxidation of betacyanins, namely, plant pigment betanin and its derivatives, 2-decarboxybetanin, 17-decarboxybetanin, 2,17-bidecarboxybetanin, and neobetanin, was investigated in the presence of $\mathrm{ABTS}^{\bullet+}$ (ABTS/PP) cation radicals (Figure 13) [141]. The nonenzymatic oxidation mechanism was thoroughly investigated by HPLC-diode-array detection (DAD)-ESI-MS/MS.

Rather than describing all the oxidation pathways of each tested compound carefully outlined in this study, we would prefer to focus on the fact that no adduction products were detected. All the aforementioned compounds for which $\mathrm{ABTS}^{\bullet+}$ adducts have been elucidated (catechin, phloroglucinol, 
quercetin, and its 3-O-glycosides, 2,6-diisopropylphenol, guaiacylglycerol- $\beta$-guaiacyl ether, and arbutin) are phenolics. Compounds that did not couple are doxorubicin, whose phenolic ring does not have appropriate sites of coupling, and melatonin, the non-phenolic compound. However, although betanin and its derivatives have free phenolic hydroxyl, structurally they are very close to GBG, and thus there is the question as to what the structural limitations are that interfere with $\mathrm{ABTS}^{\bullet+}$ coupling. We can speculate that these are the glucoside-substitution and the only ortho to hydroxy group-free position, which together sterically hinder $\mathrm{ABTS}^{\bullet+}$ attack, but undoubtedly further investigations are needed.

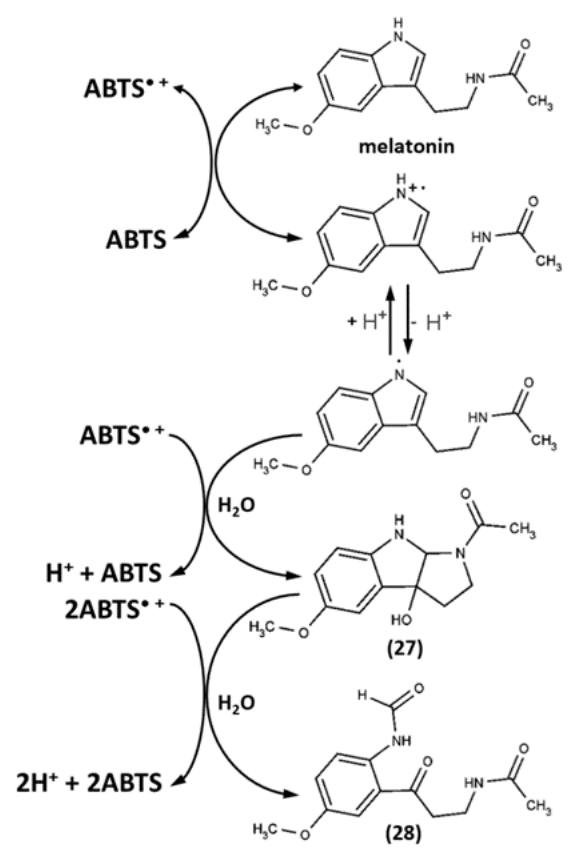

Figure 12. Reaction pathways of melatonin oxidation by ABTS ${ }^{\bullet+}$ [136]. Copyright 2003, adopted with permission from John Wiley \& Sons Ltd.

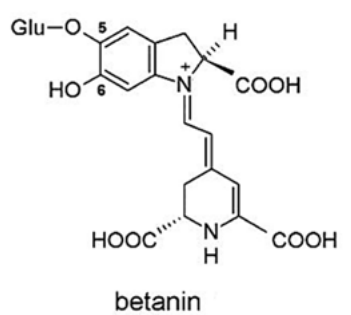

betanin

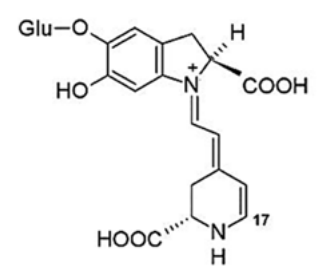

17-decarboxy-betanin<smiles>COc1cc2ccn(C=C3C=C(C(=O)O)NC(C(=O)O)C3)cc-2c1</smiles>

2-decarboxy-betanin

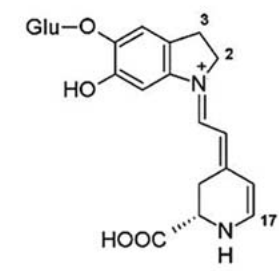

2,17-bidecarboxy-betanin<smiles></smiles>

neobetanin

Figure 13. Structures of betacyanins investigated applying ABTS/PP assay [141]. Copyright 2013, adapted with permission from American Chemical Society.

Returning to Arnao's group study devoted to ABTS ${ }^{\bullet+}$-flavonoid complexes, several structural limitations were insightfully indicated $[107,108]$. On the basis of absorption spectra differences, they deduced that both A- and B-rings could act in complex formation, with mono- or dihydroxy substitution in the B-ring and/or 5,7-dihydroxy substitution in the A-ring favoring $\mathrm{ABTS}^{\bullet+}$-flavonoid complex 
formation. In contrast, methylation of one hydroxyl in the B-ring, as well as 7-O-glycosylation of the A-ring, impeded their development; therefore, when these occurred together, namely, in the cases of hesperidin, neohesperidin, and poncirin, no complex formation was detected (Figure 14).

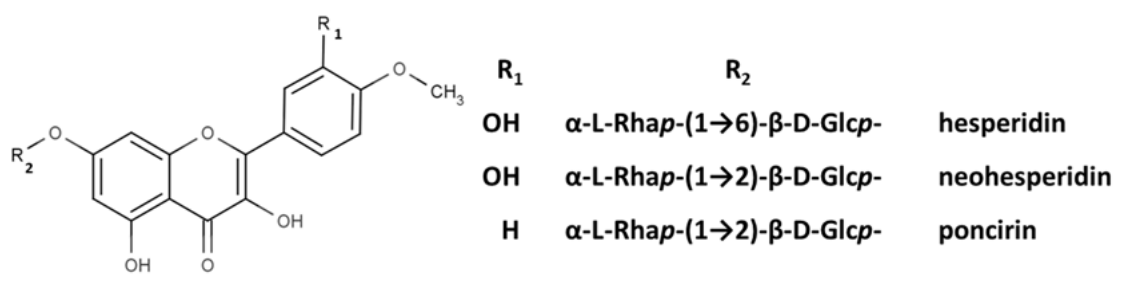

Figure 14. Chemical structures of hesperidin, neohesperidin, and poncirin.

Another important point is the question of coupling adduct formation impact on $\mathrm{ABTS}^{\bullet+}$-based assays in general and, particularly, the high stoichiometries obtained. Opposite to the works described above, some of which detected adduct formation almost quantitatively so that $\mathrm{ABTS}^{\bullet+}$ was consumed at least partly not to regenerate ABTS, several studies reported practically complete conversion of ABTS $^{\bullet+}$ back to ABTS $[55,142]$. Is this the situation for all cases where no adducts are formed, that is, does the absence of adducts indicate that $\mathrm{ABTS}^{\bullet+}$ was fully converted back to ABTS? This is another interesting issue for further elucidation.

\section{Conclusions}

Generally, the chemistry lying behind the usually oversimplified ABTS $^{\bullet+}$ scavenging by antioxidants is still not defined, despite the fact that the $\mathrm{ABTS}^{\bullet+}$-based assays are among the most abundant antioxidant capacity assays, together with the DPPH-based assays.

Several hypotheses can be suggested concerning antioxidant-ABTS ${ }^{\bullet+}$ reaction pathways for further elucidation:

(1) Some antioxidants can form adducts with $\mathrm{ABTS}^{\bullet+}$, whereas others can undergo oxidation without coupling with $\mathrm{ABTS}^{\bullet+}$. Thus, coupling with $\mathrm{ABTS}^{\bullet+}$ is a specific reaction for certain groups of antioxidants, apparently at least of phenolic nature. Establishing the structural features that determine the direction of antioxidant interaction with $\mathrm{ABTS}^{\bullet+}$ is important for future understanding and interpretation of antioxidant capacity measurements.

(2) Adduct-free oxidation pathways are substrate-specific and can be influenced both by ABTS ${ }^{\bullet+}$ radical specific features or by the radical-initiator system. However, they seem to be reliably consistent with the results obtained when other oxidants are applied instead of ABTS ${ }^{\bullet+}$.

(3) The coupling reaction can occur with phenolic compounds, and the coupling adduct can be the principal product as well as undergoing further oxidative degradation, which might depend on the antioxidant/ABTS ${ }^{\bullet+}$ ratio and $\mathrm{ABTS}^{\bullet+}$ generation methodology.

(4) Further oxidative degradation of the coupling product results from the oxidative cleavage between the two nitrogen-linked benzothiazole rings. This leads to hydrazindyilidene-like and imine-like adduct formation. 3-Ethyl-2-oxo-1,3-benzothiazoline-6-sulfonate can presumably witness a hydrazindyilidene-like adduct formation pathway, whereas 3-ethyl-2-imino-1,3benzothiazoline-6-sulfonate testifies to the imine-like adduct formation pathway.

(5) The extent that the coupling reaction contributes to the reaction between antioxidants and ABTS ${ }^{\bullet+}$ (e.g., kinetics and stoichiometry) is unclear due to the lack of quantitative estimation of their formation, and sometimes this may be quite considerable.

As for our opinion, undoubtedly there are questions in terms of the overall application of ABTS/PP assay, and this review adds to them, as the specifics for certain compound reactions, such as coupling, might bias the comparison of different antioxidants. Nevertheless, the ABTS-based assays can still be used with certain reservations, as was stated earlier, particularly for tracking changes in the 
same antioxidant system-for example, during storage and processing-or for composition effect evaluation. In addition, $\mathrm{ABTS}^{\bullet+}$-mediated reactions can provide a perspective from other points of view, for instance, as a means for flavonoid analysis, and are, therefore, interesting to elucidate further.

Author Contributions: Conceptualization, I.R.I. and I.A.S.; data curation, I.R.I.; writing-original draft preparation, I.R.I.; writing-review and editing, I.A.S., V.L.B., I.A.S., and R.P.T.; visualization, R.P.T.; supervision, V.L.B. All authors have reviewed the manuscript. All authors have read and agreed to the published version of the manuscript.

Funding: This research was funded by the Russian Academic Excellence Project 5-100.

Conflicts of Interest: The authors declare no conflict of interest.

\section{Abbreviations}

ABTS

AFMK

c3OHM

CEP

COSY

CUPRAC

DAD

$\mathrm{DPPH}$

ESI-HRMS

ESI-MS

ET-PT

FRAP

FKBP

GBG

GBGox

GSH

GSSG

HAT

HMBC

HSQC

HPLC-ECD

HPLC-UV

$\mathrm{IC}_{50}$

IR

MS-MS

NI

NMR

ORAC

PBS

PDA

PI

PP

QTOF-MS

RP-UHPLC

SET

SIMS

SPLET

TEAC

TLC

UV-VIS 2,2'-azino-bis(3-ethylbenzothiazoline-6-sulfonic acid) diammonium salt

N1-acetyl-N2-formyl-5-methoxykynuramine

cyclic 3-hydroxymelatonin

concerted electron-proton transfer

correlation spectroscopy

cupric reducing antioxidant capacity

diode-array detection

2,2-diphenyl-1-picrylhydrazyl

high resolution electrospray ionization mass spectrometry

electrospray ionization mass spectrometry

electron transfer-proton transfer

ferric reducing antioxidant power

fujimycin binding protein

guaiacylglycerol- $\beta$-guaiacyl ether

oxidation products of guaiacylglycerol- $\beta$-guaiacyl ether

glutathione

glutathione disulfide

hydrogen atom transfer

heteronuclear multiple bond correlation

heteronuclear single quantum coherence

high performance liquid chromatography, electrochemical detection

high performance liquid chromatography, ultraviolet detection

concentration which leads to $50 \%$ inhibition

infrared spectroscopy

tandem mass spectrometry

negative mode in electrospray ionization mass spectrometry

nuclear magnetic resonance

oxygen radical absorbance capacity

phosphate buffer solution

photodiode array

positive mode in electrospray ionization mass spectrometry

potassium persulfate

quadrupole time of flight mass spectrometer

reversed-phase ultrahigh-performance liquid chromatography

single electron transfer

secondary ion mass spectrometry

sequential proton loss electron transfer

trolox equivalent antioxidant capacity

thin layer chromatography

ultraviolet-visible spectroscopy 


\section{References}

1. Re, R.; Pellegrini, N.; Proteggente, A.; Pannala, A.; Yang, M.; Rice-Evans, C. Antioxidant activity applying an improved ABTS radical cation decolorization assay. Free Radic. Biol. Med. 1999, 26, 1231-1237. [CrossRef]

2. Miller, N.J.; Rice-Evans, C.; Davies, M.J.; Gopinathan, V.; Milner, A. A Novel Method for Measuring Antioxidant Capacity and its Application to Monitoring the Antioxidant Status in Premature Neonates. Clin. Sci. 1993, 84, 407-412. [CrossRef] [PubMed]

3. Cano, A.; Arnao, M.B. ABTS/TEAC (2,2'-azino-bis(3-ethylbenzothiazoline-6-sulfonic acid)/Trolox ${ }^{\circledR}$. Equivalent Antioxidant Capacity) radical scavenging mixed-mode assay. In Measurement of Antioxidant Activity \& Capacity; John Wiley \& Sons, Ltd.: Chichester, UK, 2017; pp. 117-139. ISBN 9781119135388.

4. Schaich, K.M.; Tian, X.; Xie, J. Hurdles and pitfalls in measuring antioxidant efficacy: A critical evaluation of ABTS, DPPH, and ORAC assays. J. Funct. Foods 2015, 14, 111-125. [CrossRef]

5. Apak, R. Current Issues in Antioxidant Measurement. J. Agric. Food Chem. 2019, 67, 9187-9202. [CrossRef]

6. Gülçin, I. Antioxidant activity of food constituents: An overview. Arch. Toxicol. 2012, 86, 345-391. [CrossRef]

7. Shahidi, F.; Zhong, Y. Measurement of antioxidant activity. J. Funct. Foods 2015, 18, 757. [CrossRef]

8. López-Alarcón, C.; Denicola, A. Evaluating the antioxidant capacity of natural products: A review on chemical and cellular-based assays. Anal. Chim. Acta 2013, 763, 1-10. [CrossRef]

9. Apak, R.; Özyürek, M.; Güçlü, K.; Çapanoğlu, E. Antioxidant Activity/Capacity Measurement. 2. Hydrogen Atom Transfer (HAT)-Based, Mixed-Mode (Electron Transfer (ET)/HAT), and Lipid Peroxidation Assays. J. Agric. Food Chem. 2016, 64, 1028-1045. [CrossRef]

10. Apak, R.; Özyürek, M.; Güçlü, K.; Çapanoğlu, E. Antioxidant Activity/Capacity Measurement. 1. Classification, Physicochemical Principles, Mechanisms, and Electron Transfer (ET)-Based Assays. J. Agric. Food Chem. 2016, 64, 997-1027. [CrossRef]

11. Niki, E. Assessment of antioxidant capacity in vitro and in vivo. Free Radic. Biol. Med. 2010, 49, 503-515. [CrossRef]

12. Pellegrini, N.; Vitaglione, P.; Granato, D.; Fogliano, V. Twenty-five years of total antioxidant capacity measurement of foods and biological fluids: Merits and limitations. J. Sci. Food Agric. 2019. [CrossRef] [PubMed]

13. Li, B.; Pratt, D.A. Methods for determining the efficacy of radical-trapping antioxidants. Free Radic. Biol. Med. 2015. [CrossRef] [PubMed]

14. Ingold, K.U.; Pratt, D.A. Advances in Radical-Trapping Antioxidant Chemistry in the 21st Century: A Kinetics and Mechanisms Perspective. Chem. Rev. 2014, 114, 9022-9046. [CrossRef] [PubMed]

15. Apak, R.; Capanoglu, E.; Shahidi, F. Measurement of Antioxidant Activity E Capacity. Recent Trends and Applications; Apak, R., Capanoglu, E., Shahidi, F., Eds.; John Wiley \& Sons, Ltd.: Chichester, UK, 2018; ISBN 9781119135388.

16. Erel, O. A novel automated direct measurement method for total antioxidant capacity using a new generation, more stable ABTS radical cation. Clin. Biochem. 2004, 37, 277. [CrossRef]

17. Brand-Williams, W.; Cuvelier, M.E.; Berset, C. Use of a free radical method to evaluate antioxidant activity. LWT-Food Sci. Technol. 1995, 28, 25-30. [CrossRef]

18. Yamaguchi, T.; Takamura, H.; Matoba, T.; Terao, J. Hplc method for evaluation of the free radical-scavenging activity of foods by using 1,1-diphenyl-2-picrylhydrazyl. Biosci. Biotechnol. Biochem. 1998, 62, 1201-1204. [CrossRef]

19. Sanchez-Moreno, C.; Larrauri, J.A.; Saura-Calixto, F.A. A procedure to measure the antiradical efficiency of polyphenols. J. Sci. Food Agric. 1998, 76, 270. [CrossRef]

20. Sharma, O.P.; Bhat, T.K. DPPH antioxidant assay revisited. Food Chem. 2009, 113, 1202-1205. [CrossRef]

21. Benzie, I.F.F.; Strain, J.J. The ferric reducing ability of plasma (FRAP) as a measure of 'antioxidant power': The FRAP assay. Anal. Biochem. 1996, 239, 70. [CrossRef]

22. Benzie, I.F.; Strain, J.J. Ferric reducing/antioxidant power assay: Direct measure of total antioxidant activity of biological fluids and modified version for simultaneous measurement of total antioxidant power and ascorbic acid concentration. Methods Enzym. 1999, 299, 15.

23. Pulido, R.; Bravo, L.; Saura-Calixto, F. Antioxidant activity of dietary polyphenols as determined by a modified ferric reducing/antioxidant power assay. J. Agric. Food Chem. 2000, 48, 3396. [CrossRef] [PubMed] 
24. Singleton, V.L.; Orthofer, R.; Lamuela-Raventos, R.M. Analysis of total phenols and other oxidation substrates and antioxidants by means of Folin-Ciocalteu reagent. Methods Enzym. 1999, 299, 152.

25. Ainsworth, E.A.; Gillespie, K.M. Estimation of total phenolic content and other oxidation substrates in plant tissues using Folin-Ciocalteu reagent. Nat. Protoc. 2007, 2, 875-877. [CrossRef] [PubMed]

26. Georgé, S.; Brat, P.; Alter, P.; Amiot, M.J. Rapid determination of polyphenols and vitamin C in plant-derived products. J. Agric. Food Chem. 2005, 53, 1370-1373. [CrossRef] [PubMed]

27. Medina-Remón, A.; Barrionuevo-González, A.; Zamora-Ros, R.; Andres-Lacueva, C.; Estruch, R.; Martínez-González, M.-Á.; Diez-Espino, J.; Lamuela-Raventos, R.M. Rapid Folin-Ciocalteu method using microtiter 96-well plate cartridges for solid phase extraction to assess urinary total phenolic compounds, as a biomarker of total polyphenols intake. Anal. Chim. Acta 2009, 634, 54-60. [CrossRef]

28. Cao, G.; Alessio, H.M.; Cutler, R.G. Oxygen-radical absorbance capacity assay for antioxidants. Free Radic. Biol. Med. 1993, 14, 303-311. [CrossRef]

29. Cao, G.; Verdon, C.P.; Wu, A.H.; Wang, H.; Prior, R.L. Automated oxygen radical absorbance capacity assay using the COBAS FARA II. Clin. Chem. 1995, 41, 1738. [CrossRef]

30. Dávalos, A.; Gómez-Cordovés, C.; Bartolomé, B. Extending Applicability of the Oxygen Radical Absorbance Capacity (ORAC-Fluorescein) Assay. J. Agric. Food Chem. 2004, 52, 48-54. [CrossRef]

31. Huang, D.; Ou, B.; Hampsch-Woodill, M.; Flanagan, J.A.; Prior, R.L. High-throughput assay of oxygen radical absorbance capacity (ORAC) using a multichannel liquid handling system coupled with a microplate fluorescence reader in 96-well format. J. Agric. Food Chem. 2002, 50, 4437-4444. [CrossRef]

32. Ou, B.; Hampsch-Woodill, M.; Prior, R.L. Development and validation of an improved oxygen radical absorbance capacity assay using fluorescein as the fluorescent probe. J. Agric. Food Chem. 2001. [CrossRef]

33. Huang, D.; Ou, B.; Hampsch-Woodill, M.; Flanagan, J.A.; Deemer, E.K. Development and validation of oxygen radical absorbance capacity assay for lipophilic antioxidants using randomly methylated $\beta$-cyclodextrin as the solubility enhancer. J. Agric. Food Chem. 2002. [CrossRef] [PubMed]

34. Apak, R.; Güçlü, K.; Özyürek, M.; Karademir, S.E. Novel Total Antioxidant Capacity Index for Dietary Polyphenols and Vitamins C and E, Using Their Cupric Ion Reducing Capability in the Presence of Neocuproine: CUPRAC Method. J. Agric. Food Chem. 2004, 52, 7970-7981. [CrossRef] [PubMed]

35. Apak, R.; Güçlü, K.; Özyürek, M.; Karademir, S.E.; Altun, M. Total antioxidant capacity assay of human serum using copper(II)-neocuproine as chromogenic oxidant: The CUPRAC method. Free Radic. Res. 2005, 39, 949-961. [CrossRef] [PubMed]

36. Apak, R.; Güçlü, K.; Demirata, B.;Özyürek, M.; Çelik, S.E.; Bektaşoğlu, B.; Berker, K.I.; Özyurt, D. Comparative evaluation of various total antioxidant capacity assays applied to phenolic compounds with the CUPRAC assay. Molecules 2007, 12, 1496-1547. [CrossRef]

37. Arnao, M.B. Some methodological problems in the determination of antioxidant activity using chromogen radicals: A practical case. Trends Food Sci. Technol. 2000, 11, 419. [CrossRef]

38. Dong, J.-W.; Cai, L.; Xing, Y.; Yu, J.; Ding, Z.-T. Re-evaluation of ABTS•+ Assay for Total Antioxidant Capacity of Natural Products. Nat. Prod. Commun. 2015. [CrossRef]

39. Dawidowicz, A.L.; Olszowy, M. The importance of solvent type in estimating antioxidant properties of phenolic compounds by ABTS assay. Eur. Food Res. Technol. 2013, 236, 1099-1105. [CrossRef]

40. Solís-Oba, M.; Ugalde-Saldívar, V.M.; González, I.; Viniegra-González, G. An electrochemicalspectrophotometrical study of the oxidized forms of the mediator 2,2'-azino-bis-(3-ethylbenzothiazoline-6sulfonic acid) produced by immobilized laccase. J. Electroanal. Chem. 2005, 579, 59-66. [CrossRef]

41. Venkatasubramanian, L.; Maruthamuthu, P. Kinetics and mechanism of formation and decay of 2,2'-azinobis-(3-ethylbenzothiazole-6-sulphonate) radical cation in aqueous solution by inorganic peroxides. Int. J. Chem. Kinet. 1989, 21, 399-421. [CrossRef]

42. Scott, S.L.; Chen, W.J.; Bakac, A.; Espenson, J.H. Spectroscopic parameters, electrode potentials, acid ionization constants, and electron exchange rates of the 2,2'-azinobis(3-ethylbenzothiazoline-6-sulfonate) radicals and ions. J. Phys. Chem. 1993, 97, 6710-6714. [CrossRef]

43. Childs, R.E.; Bardsley, W.G. The steady-state kinetics of peroxidase with 2,2'-azino-di-(3-ethyl-benzthiazoline6-sulphonic acid) as chromogen. Biochem. J. 1975, 145, 93-103. [CrossRef] [PubMed]

44. Wolfenden, B.S.; Willson, R.L. Radical-cations as reference chromogens in kinetic studies of ono-electron transfer reactions: Pulse radiolysis studies of 2,2' -azinobis-(3-ethylbenzthiazoline-6-sulphonate). J. Chem. Soc. Perkin Trans. 2 1982, 805-812. [CrossRef] 
45. Cano, A.; Acosta, M.; Arnao, M.B. A method to measure antioxidant activity in organic media: Application to lipophilic vitamins. Redox Rep. 2000, 5, 365-370. [CrossRef] [PubMed]

46. Henriquez, C.; Aliaga, C.; Lissi, E. Formation and decay of the ABTS derived radical cation: A comparison of different preparation procedures. Int. J. Chem. Kinet. 2002, 34, 659-665. [CrossRef]

47. Maruthamuthu, P.; Venkatasubramanian, L.; Dharmalingam, P. A Fast Kinetic Study of Formation and Decay of 2,2'-Azinobis(3-ethylbenzothiazole-6-sulfonate) Radical Cation in Aqueous Solution. Bull. Chem. Soc. Jpn. 1987, 60, 1113-1117. [CrossRef]

48. Gramss, G. Reappraising a controversy: Formation and role of the azodication (ABTS 2+ ) in the laccase-ABTS catalyzed breakdown of lignin. Fermentation 2017, 3, 27. [CrossRef]

49. Mahuzier, G.; Kirkacharian, B.S.; Harfouche-Obeika, C. Microdosage colorimétrique de l'acide periodique par l'acide 2,2'-azino-di(3-ethylbenzothiazole-6-sulfonique). Anal. Chim. Acta 1975. [CrossRef]

50. Majcherczyk, A.; Johannes, C.; Hüttermann, A. Oxidation of aromatic alcohols by laccase from Trametes versicolor mediated by the 2,2'-azino-bis-(3-ethylbenzothiazoline-6-sulphonic acid) cation radical and dication. Appl. Microbiol. Biotechnol. 1999, 51, 267-276. [CrossRef]

51. Branchi, B.; Galli, C.; Gentili, P. Kinetics of oxidation of benzyl alcohols by the dication and radical cation of ABTS. Comparison with laccase-ABTS oxidations: An apparent paradox. Org. Biomol. Chem. 2005. [CrossRef]

52. van den Berg, R.; Haenen, G.R.M.M.; van den Berg, H.; Bast, A. Applicability of an improved Trolox equivalent antioxidant capacity (TEAC) assay for evaluation of antioxidant capacity measurements of mixtures. Food Chem. 1999, 66, 511-517. [CrossRef]

53. Aliaga, C.; Lissi, E.A. Reaction of 2,2'-azinobis 3-ethylbenzothiazoline-6-sulfonic acid (ABTS) derived radicals with hydroperoxides. Kinetics and mechanism. Int. J. Chem. Kinet. 1998, 30, 565-570. [CrossRef]

54. Campos, A.M.; Lissi, E.A. Kinetics of the reaction between 2,2'-azinobis-(3-ethylbenzothiazoline-6-sulfonic acid (ABTS) derived radical cations and phenols. Int. J. Chem. Kinet. 1997, 29, 219. [CrossRef]

55. Aliaga, C.; Lissi, E.A. Reactions of the radical cation derived from 2,2'-azinobis(3-ethylbenzothiazoline6-sulfonic acid) $\left(\mathrm{ABTS}^{+}\right.$) with amino acids. Kinetics and mechanism. Can. J. Chem. 2000, 78, 1052-1059. [CrossRef]

56. Klein, O.I.; Kulikova, N.A.; Filimonov, I.S.; Koroleva, O.V.; Konstantinov, A.I. Long-term kinetics study and quantitative characterization of the antioxidant capacities of humic and humic-like substances. J. Soils Sediments 2018, 18, 1355-1364. [CrossRef]

57. Tian, X.; Schaich, K.M. Effects of molecular structure on kinetics and dynamics of Trolox Equivalent Antioxidant Capacity (TEAC) Assay with ABTS +•. J. Agric. Food Chem. 2013, 61, 5511-5519. [CrossRef] [PubMed]

58. Ilyasov, I.R.; Beloborodov, V.L.; Selivanova, I.A. Three ABTS $\bullet+$ radical cation-based approaches for the evaluation of antioxidant activity: Fast- and slow-reacting antioxidant behavior. Chem. Pap. 2018, 72, 1917-1925. [CrossRef]

59. Rosen, J.; Than, N.N.; Koch, D.; Poeggeler, B.; Laatsch, H.; Hardeland, R. Interactions of melatonin and its metabolites with the ABTS cation radical: Extension of the radical scavenger cascade and formation of a novel class of oxidation products, C2-substituted 3-indolinones. J. Pineal Res. 2006, 41, 374-381. [CrossRef]

60. Walker, R.B.; Everette, J.D. Comparative reaction rates of various antioxidants with ABTS radical cation. J. Agric. Food Chem. 2009, 57, 1156-1161. [CrossRef]

61. Magalhaes, L.M.; Segundo, M.A.; Reis, S.; Lima, J.L.F.C. Methodological aspects about in vitro evaluation of antioxidant properties. Anal. Chim. Acta 2008, 613, 1. [CrossRef]

62. Zheng, L.; Zhao, M.; Xiao, C.; Zhao, Q.; Su, G. Practical problems when using ABTS assay to assess the radical-scavenging activity of peptides: Importance of controlling reaction $\mathrm{pH}$ and time. Food Chem. 2016, 192, 288-294. [CrossRef]

63. Takebayashi, J.; Tai, A.; Yamamoto, I. pH-dependent long-term radical scavenging activity of AA-2G and 6-octa-AA-2G against 2,2'-azinobis(3-ethylbenzothiazoline-6-sulfonic acid) radical cation. Biol. Pharm. Bull. 2003, 26, 1368-1370. [CrossRef] [PubMed]

64. Arts, M.J.T.J.; Haenen, G.R.M.M.; Voss, H.P.; Bast, A. Antioxidant capacity of reaction products limits the applicability of the Trolox Equivalent Antioxidant Capacity (TEAC) assay. Food Chem. Toxicol. 2004, 42, 45-49. [CrossRef] [PubMed] 
65. Arts, M.J.T.J.; Sebastiaan Dallinga, J.; Voss, H.P.; Haenen, G.R.M.M.; Bast, A. A new approach to assess the total antioxidant capacity using the TEAC assay. Food Chem. 2004, 88, 567-570. [CrossRef]

66. Çelik, S.E.; Özyürek, M.; Güçlü, K.; Apak, R. Solvent effects on the antioxidant capacity of lipophilic and hydrophilic antioxidants measured by CUPRAC, ABTS/persulphate and FRAP methods. Talanta 2010, 81, 1300. [CrossRef] [PubMed]

67. Błauz, A.; Pilaszek, T.; Grzelak, A.; Dragan, A.; Bartosz, G. Interaction between antioxidants in assays of total antioxidant capacity. Food Chem. Toxicol. 2008, 46, 2365-2368. [CrossRef] [PubMed]

68. Giles, G.I.; Jacob, C. Reactive sulfur species: An emerging concept in oxidative stress. Biol. Chem. 2002, 383, 375-388. [CrossRef] [PubMed]

69. Van Den Berg, R.; Haenen, G.R.M.M.; Van Den Berg, H.; Van Der Vijgh, W.; Bast, A. The predictive value of the antioxidant capacity of structurally related flavonoids using the Trolox equivalent antioxidant capacity (TEAC) assay. Food Chem. 2000, 70, 391-395. [CrossRef]

70. Rice-Evans, C.A.; Miller, N.J.; Paganga, G. Antioxidant properties of phenolic compounds. Trends Plant Sci. 1997, 2, 152-159. [CrossRef]

71. Nenadis, N.; Wang, L.F.; Tsimidou, M.; Zhang, H.Y. Estimation of scavenging activity of phenolic compounds using the ABTS.+ assay. J. Agric. Food Chem. 2004. [CrossRef]

72. Henriquez, C.; Aliaga, C.; Lissi, E. Kinetics profiles in the reaction of ABTS derived radicals with simple phenols and polyphenols. J. Chil. Chem. Soc. 2004, 49, 65-67. [CrossRef]

73. Mira, L.; Silva, M.; Rocha, R.; Manso, C.F. Measurement of relative antioxidant activity of compounds: A methodological note. Redox Rep. 1999, 4, 69-74. [CrossRef] [PubMed]

74. Sekher Pannala, A.; Chan, T.S.; O’Brien, P.J.; Rice-Evans, C.A. Flavonoid B-ring chemistry and antioxidant activity: Fast reaction kinetics. Biochem. Biophys. Res. Commun. 2001, 282, 1161-1168. [CrossRef] [PubMed]

75. Osman, A.M.; Wong, K.K.Y.; Hill, S.J.; Fernyhough, A. Isolation and the characterization of the degradation products of the mediator ABTS-derived radicals formed upon reaction with polyphenols. Biochem. Biophys. Res. Commun. 2006, 340, 597-603. [CrossRef] [PubMed]

76. Rice-evans, C.A.; Miller, N.J.; Bolwell, P.G.; Bramley, P.M.; Pridham, J.B. The relative antioxidant activities of plant-derived polyphenolic flavonoids. Free Radic. Res. 1995. [CrossRef]

77. Rice-Evans, C.A.; Miller, N.J.; Paganga, G. Structure-antioxidant activity relationships of flavonoids and phenolic acids. Free Radic. Biol. Med. 1996, 20, 933-956. [CrossRef]

78. Munk, L.; Sitarz, A.K.; Kalyani, D.C.; Mikkelsen, J.D.; Meyer, A.S. Can laccases catalyze bond cleavage in lignin? Biotechnol. Adv. 2015, 33, 13-24. [CrossRef]

79. Rodríguez Couto, S.; Toca Herrera, J.L. Industrial and biotechnological applications of laccases: A review. Biotechnol. Adv. 2006, 24, 500-513. [CrossRef]

80. Ramalingam, B.; Sana, B.; Seayad, J.; Ghadessy, F.J.; Sullivan, M.B. Towards understanding of laccase-catalysed oxidative oligomerisation of dimeric lignin model compounds. RSC Adv. 2017, 7, 11951-11958. [CrossRef]

81. Rittstieg, K.; Suurnakki, A.; Suortti, T.; Kruus, K.; Guebitz, G.M.; Buchert, J. Polymerization of Guaiacol and a Phenolic $\beta$-O-4-Substructure by Trametes hirsuta Laccase in the Presence of ABTS. Biotechnol. Prog. 2003, 19, 1505-1509. [CrossRef]

82. Bourbonnais, R.; Paice, M.G. Oxidation of non-phenolic substrates. FEBS Lett. 1990, 267, 99-102. [CrossRef]

83. Osman, A.M.; Wong, K.K.Y.; Fernyhough, A. ABTS radical-driven oxidation of polyphenols: Isolation and structural elucidation of covalent adducts. Biochem. Biophys. Res. Commun. 2006, 346, 321-329. [CrossRef]

84. Heim, K.E.; Tagliaferro, A.R.; Bobilya, D.J. Flavonoid antioxidants: Chemistry, metabolism and structure-activity relationships. J. Nutr. Biochem. 2002, 13, 572-584. [CrossRef]

85. Mukai, K.; Oka, W.; Watanabe, K.; Egawa, Y.; Nagaoka, S. Kinetic study of free-radical-scavenging action of flavonoids in homogeneous and aqueous triton X-100 micellar solutions. J. Phys. Chem. A 1997, 101, 3746. [CrossRef]

86. Mitani, S.; Ouchi, A.; Watanabe, E.; Kanesaki, Y.; Nagaoka, S.I.; Mukai, K. Stopped-flow kinetic study of the aroxyl radical-scavenging action of catechins and vitamin $\mathrm{C}$ in ethanol and micellar solutions. J. Agric. Food Chem. 2008. [CrossRef] [PubMed]

87. Zhang, M.; Vervoort, L.; Moalin, M.; Mommers, A.; Douny, C.; den Hartog, G.J.M.; Haenen, G.R.M.M. The chemical reactivity of (-)-epicatechin quinone mainly resides in its B-ring. Free Radic. Biol. Med. 2018, 124, 31-39. [CrossRef] [PubMed] 
88. Ruijters, E.J.B.; Weseler, A.R.; Kicken, C.; Haenen, G.R.M.M.; Bast, A. The flavanol (-)-epicatechin and its metabolites protect against oxidative stress in primary endothelial cells via a direct antioxidant effect. Eur. J. Pharmacol. 2013, 715, 147-153. [CrossRef] [PubMed]

89. Huang, D.; Ou, B.; Prior, R.L. The chemistry behind antioxidant capacity assays. J. Agric. Food Chem. 2005, 53, 1841. [CrossRef]

90. Prior, R.L.; Wu, X.; Schaich, K. Standardized methods for the determination of antioxidant capacity and phenolics in foods and dietary supplements. J. Agric. Food Chem. 2005. [CrossRef]

91. Apak, R.; Gorinstein, S.; Böhm, V.; Schaich, K.M.; Özyürek, M.; Güçlü, K. Methods of measurement and evaluation of natural antioxidant capacity/activity (IUPAC Technical Report)*. Pure Appl. Chem 2013, 85, 957-998. [CrossRef]

92. Fabbrini, M.; Galli, C.; Gentili, P. Radical or electron-transfer mechanism of oxidation with some laccase/mediator systems. J. Mol. Catal. B Enzym. 2002, 18, 169-171. [CrossRef]

93. Litwinienko, G.; Ingold, K.U. Solvent effects on the rates and mechanisms of reaction of phenols with free radicals. Acc. Chem. Res. 2007. [CrossRef] [PubMed]

94. Litwinienko, G.; Ingold, K.U. Abnormal solvent effects on hydrogen atom abstraction. 2. Resolution of the curcumin antioxidant controversy. The role of sequential proton loss electron transfer. J. Org. Chem. 2004, 69, 5888-5896. [CrossRef] [PubMed]

95. Foti, M.C.; Daquino, C.; Geraci, C. Electron-Transfer Reaction of Cinnamic Acids and Their Methyl Esters with the DPPH • Radical in Alcoholic Solutions. J. Org. Chem. 2004, 69, 2309-2314. [CrossRef] [PubMed]

96. Di Meo, F.; Lemaur, V.; Cornil, J.; Lazzaroni, R.; Duroux, J.-L.; Olivier, Y.; Trouillas, P. Free radical scavenging by natural polyphenols: Atom versus electron transfer. J. Phys. Chem. A 2013, 117, 2082. [CrossRef]

97. Cren-Olivé, C.; Wieruszeski, J.M.; Maes, E.; Rolando, C. Catechin and epicatechin deprotonation followed by 13C NMR. Tetrahedron Lett. 2002. [CrossRef]

98. Cren-Olivé, C.; Lebrun, S.; Hapiot, P.; Pinson, J.; Rolando, C. Selective protection of catechin gives access to the intrinsic reactivity of the two phenol rings during $\mathrm{H}$-abstraction and photo-oxidation. Tetrahedron Lett. 2000. [CrossRef]

99. Dangles, O.; Fargeix, G.; Dufour, C. One-electron oxidation of quercetin and quercetin derivatives in protic and non protic media. J. Chem. Soc. Perkin Trans. 2 1999, 1387-1396. [CrossRef]

100. Lluís Torres, J.; Carreras, A.; Jiménez, A.; Brillas, E.; Torrelles, X.; Rius, J.; Juliá, L. Reducing Power of Simple Polyphenols by Electron-Transfer Reactions Using a New Stable Radical of the PTM Series, Tris(2,3,5,6-tetrachloro-4-nitrophenyl)methyl Radical. J. Org. Chem. 2007, 72, 3750-3756. [CrossRef]

101. Lemańska, K.; Szymusiak, H.; Tyrakowska, B.; Zieliński, R.; Soffers, A.E.M.F.; Rietjens, I.M.C.M. The influence of $\mathrm{pH}$ on antioxidant properties and the mechanism of antioxidant action of hydroxyflavones. Free Radic. Biol. Med. 2001, 31, 869-881. [CrossRef]

102. Jovanovic, S.V.; Steenken, S.; Tosic, M.; Marjanovic, B.; Simic, M.G. Flavonoids as Antioxidants. J. Am. Chem. Soc. 1994, 116, 4846-4851. [CrossRef]

103. Romero, R.; Salgado, P.R.; Soto, C.; Contreras, D.; Melin, V. An Experimental Validated Computational Method for pKa Determination of Substituted 1,2-Dihydroxybenzenes. Front. Chem. 2018. [CrossRef] [PubMed]

104. Slabbert, N.P. Ionisation of some flavanols and dihydroflavonols. Tetrahedron 1977, 33, 821-824. [CrossRef]

105. Kennedy, J.A.; Munro, M.H.G.; Powell, H.K.J.; Porter, L.J.; Foo, L.Y. The protonation reactions of catechin, epicatechin and related compounds. Aust. J. Chem. 1984, 37, 885. [CrossRef]

106. Pratt, D.A.; Dilabio, G.A.; Mulder, P.; Ingold, K.U. Bond strengths of toluenes, anilines, and phenols: To hammett or not. Acc. Chem. Res. 2004. [CrossRef] [PubMed]

107. Marín, F.R.; Hernández-Ruiz, J.; Arnao, M.B. A colorimetric method for the determination of different functional flavonoids using 2,2' -azino-bis-(3-ethylbenzthiazoline-6-sulphonic acid) (ABTS) and peroxidase. Prep. Biochem. Biotechnol. 2019, 1-7. [CrossRef] [PubMed]

108. Arnao, M.B.; Casas, J.L.; del Río, J.A.; Acosta, M.; García-Cánovas, F. An enzymatic colorimetric method for measuring naringin using 2,2'-azino-bis-(3-ethylbenzthiazoline-6-sulfonic acid) (ABTS) in the presence of peroxidase. Anal. Biochem. 1990, 185, 335-338. [CrossRef]

109. Hotta, H.; Nagano, S.; Ueda, M.; Tsujino, Y.; Koyama, J.; Osakai, T. Higher radical scavenging activities of polyphenolic antioxidants can be ascribed to chemical reactions following their oxidation. Biochim. Biophys. Acta-Gen. Subj. 2002, 1572, 123-132. [CrossRef] 
110. Hotta, H.; Sakamoto, H.; Nagano, S.; Osakai, T.; Tsujino, Y. Unusually large numbers of electrons for the oxidation of polyphenolic antioxidants. Biochim. Biophys. Acta Gen. Subj. 2001, 1526, 159. [CrossRef]

111. Osman, A.M.; Wong, K.K.Y.; Fernyhough, A. The laccase/ABTS system oxidizes (+)-catechin to oligomeric products. Enzyme Microb. Technol. 2007, 40, 1272-1279. [CrossRef]

112. Bourbonnais, R.; Paice, M.G.; Reid, I.D.; Lanthier, P.; Yaguchi, M. Lignin oxidation by laccase isozymes from Trametes versicolor and role of the mediator 2,2'-azinobis(3-ethylbenzthiazoline-6-sulfonate) in kraft lignin depolymerization. Appl. Environ. Microbiol. 1995, 61, 1876-1880. [CrossRef]

113. Murao, S.; Matsumura, E.; Yamamoto, E.; Tanaka, N.; Shin, T. Substrate Specificity of Bilirubin Oxidase and Phenol Oxidase: Coloration Reaction against Benzoic Acid Derivatives. Yakugaku Zasshi 1985, 105, 86-90. [CrossRef] [PubMed]

114. Arnao, M.B.; Sanchez-Bravo, J.; Acosta, M. Indole-3-carbinol as a scavenger of free radicals. Biochem. Mol. Biol. Int. 1996, 39, 1125-1134. [CrossRef] [PubMed]

115. Matsumura, E.; Yamamoto, E.; Numata, A.; Kawano, T.; Shin, T.; Murao, S. Structures of the Laccase-catalyzed Oxidation Products of Hydroxy-benzoic Acids in the Presence of ABTS [2,2'-Azino-di-(3-ethylbenzothiazoline-6-sulfonic Acid)]. Agric. Biol. Chem. 1986, 50, 1355-1357. [CrossRef]

116. Shin, T.; Murao, S.; Matsumura, E. A chromogenic oxidative coupling reaction of laccase: Applications for laccase and angiotensin I converting enzyme assay. Anal. Biochem. 1987, 166, 380-388. [CrossRef]

117. Liu, Y.R.; Li, W.G.; Chen, L.F.; Xiao, B.K.; Yang, J.Y.; Yang, L.; Zhang, C.G.; Huang, R.Q.; Dong, J.X. ABTS+ scavenging potency of selected flavonols from Hypericum perforatum L. by HPLC-ESI/MS QQQ: Reaction observation, adduct characterization and scavenging activity determination. Food Res. Int. 2014. [CrossRef]

118. Sokolová, R.; Ramešová, Š.; Degano, I.; Hromadová, M.; Gál, M.; Abka, J. The oxidation of natural flavonoid quercetin. Chem. Commun. 2012, 48, 3433-3435. [CrossRef]

119. Khasanov, V.V.; Dychko, K.A.; Labutin, A.V.; Kravtsova, S.S.; Kuryaeva, T.T. Products of the Intermediate Oxidation of Flavonoids in Aqueous Solutions and the Determination of Their Composition by High-Performance Liquid Chromatography-Mass Spectrometry. J. Anal. Chem. 2018, 73, 1248-1252. [CrossRef]

120. Krishnamachari, V.; Levine, L.H.; Paré, P.W. Flavonoid oxidation by the radical generator AIBN: A unified mechanism for quercetin radical scavenging. J. Agric. Food Chem. 2002, 50, 4357-4363. [CrossRef]

121. Zenkevich, I.G.; Eshchenko, A.Y.; Makarova, S.V.; Vitenberg, A.G.; Dobryakov, Y.G.; Utsal, V.A. Identification of the products of oxidation of quercetin by air oxygen at ambient temperature. Molecules 2007, 12, 654-672. [CrossRef]

122. Zhou, A.; Sadik, O.A. Comparative Analysis of Quercetin Oxidation by Electrochemical, Enzymatic, Autoxidation, and Free Radical Generation Techniques: A Mechanistic Study. J. Agric. Food Chem. 2008, 56, 12081-12091. [CrossRef]

123. Foti, M.C.; Daquino, C.; Dilabio, G.A.; Ingold, K.U. Kinetics of the oxidation of quercetin by 2,2-diphenyl-1-picrylhydrazyl (dpph •). Org. Lett. 2011, 13, 4826-4829. [CrossRef] [PubMed]

124. Hvattum, E.; Stenstroøm, Y.; Ekeberg, D. Study of the reaction products of flavonols with 2,2-diphenyl-1picrylhydrazyl using liquid chromatography coupled with negative electrospray ionization tandem spectrometry. J. Mass Spectrom. 2004, 39, 1570-1581. [CrossRef] [PubMed]

125. Rice-Evans, C.; Miller, N.J. Total antioxidant status in plasma and body fluids. Methods Enzymol. 1994, 234, 279-293. [CrossRef] [PubMed]

126. Cano, A. An end-point method for estimation of the total antioxidant activity in plant material. Phytochem. Anal. 1998. [CrossRef]

127. Arnao, M.B.; Cano, A.; Acosta, M. The hydrophilic and lipophilic contribution to total antioxidant activity. Food Chem. 2001, 73, 239-244. [CrossRef]

128. Li, W.; Zhang, Y.; Liu, Y.; Yue, F.; Lu, Y.; Qiu, H.; Gao, D.; Gao, Y.; Wu, Y.; Wang, Z.; et al. In vitro kinetic evaluation of the free radical scavenging ability of propofol. Anesthesiology 2012, 116, 1258-1266. [CrossRef] [PubMed]

129. Tai, A.; Ohno, A.; Ito, H. Isolation and Characterization of the 2,2'-Azinobis(3-ethylbenzothiazoline-6-sulfonic acid) (ABTS) Radical Cation-Scavenging Reaction Products of Arbutin. J. Agric. Food Chem. 2016, 64, 7285-7290. [CrossRef]

130. Hilgers, R.; Vincken, J.P.; Gruppen, H.; Kabel, M.A. Laccase/Mediator Systems: Their Reactivity toward Phenolic Lignin Structures. ACS Sustain. Chem. Eng. 2018, 6, 2037-2046. [CrossRef] 
131. Reszka, K.J.; Britigan, B.E. Doxorubicin inhibits oxidation of 2,2'-azino-bis(3-ethylbenzothiazoline-6-sulfonate) (ABTS) by a lactoperoxidase/ $\mathrm{H} 2 \mathrm{O} 2$ system by reacting with ABTS-derived radical. Arch. Biochem. Biophys. 2007, 466, 164-171. [CrossRef]

132. Nawara, K.; Krysinski, P.; Blanchard, G.J. Photoinduced Reactivity of Doxorubicin: Catalysis and Degradation. J. Phys. Chem. A 2012, 116, 4330-4337. [CrossRef]

133. Reszka, K.J.; Wagner, B.A.; Teesch, L.M.; Britigan, B.E.; Spitz, D.R.; Burns, C.P. Inactivation of Anthracyclines by Cellular Peroxidase. Cancer Res. 2005, 65, 6346-6353. [CrossRef] [PubMed]

134. Cartoni, A.; Menna, P.; Salvatorelli, E.; Braghiroli, D.; Giampietro, R.; Animati, F.; Urbani, A.; Del Boccio, P.; Minotti, G. Oxidative degradation of cardiotoxic anticancer anthracyclines to phthalic acids: Novel function for ferrylmyoglobin. J. Biol. Chem. 2004, 279, 5088-5099. [CrossRef] [PubMed]

135. Ramu, A.; Mehta, M.M.; Liu, J.; Turyan, I.; Aleksic, A. The riboflavin-mediated photooxidation of doxorubicin. Cancer Chemother. Pharmacol. 2000, 46, 449-458. [CrossRef] [PubMed]

136. Tan, D.X.; Hardeland, R.; Manchester, L.C.; Poeggeler, B.; Lopez-Burillo, S.; Mayo, J.C.; Sainz, R.M.; Reiter, R.J. Mechanistic and comparative studies of melatonin and classic antioxidants in terms of their interactions with the ABTS cation radical. J. Pineal Res. 2003, 34, 249-259. [CrossRef]

137. Tesoriere, L.; Avellone, G.; Ceraulo, L.; D'Arpa, D.; Allegra, M.; Livrea, M.A. Oxidation of melatonin by oxoferryl hemoglobin: A mechanistic study. Free Radic. Res. 2001, 35, 633-642. [CrossRef]

138. Tan, D.X.; Manchester, L.C.; Reiter, R.J.; Plummer, B.F.; Hardies, L.J.; Weintraub, S.T.; Vijayalaxmi; Shepherd, A.M.M. A novel melatonin metabolite, cyclic 3-hydroxymelatonin: A biomarker of in vivo hydroxyl radical generation. Biochem. Biophys. Res. Commun. 1998, 253, 614-620. [CrossRef]

139. Arnao, M.B.; Hernández-Ruiz, J. Melatonin and reactive oxygen and nitrogen species: A model for the plant redox network. Melatonin Res. 2019, 2, 152-168. [CrossRef]

140. Than, N.N.; Heer, C.; Laatsch, H.; Hardeland, R. Reactions of the melatonin metabolite N1-acetyl-5-methoxykynuramine (AMK) with the ABTS cation radical: Identification of new oxidation products. Redox Rep. 2006, 11, 15-24. [CrossRef]

141. Wybraniec, S.; Starzak, K.; Skopińska, A.; Nemzer, B.; Pietrzkowski, Z.; Michałowski, T. Studies on nonenzymatic oxidation mechanisms in neobetanin, betanin, and decarboxylated betanins. J. Agric. Food Chem. 2013, 61, 6465-6476. [CrossRef]

142. Valent, I.; Topol'ská, D.; Valachová, K.; Bujdák, J.; Šoltés, L. Kinetics of ABTS derived radical cation scavenging by bucillamine, cysteine, and glutathione. Catalytic effect of $\mathrm{Cu} 2+$ ions. Biophys. Chem. 2016, 212, 9-16. [CrossRef]

(C) 2020 by the authors. Licensee MDPI, Basel, Switzerland. This article is an open access article distributed under the terms and conditions of the Creative Commons Attribution (CC BY) license (http://creativecommons.org/licenses/by/4.0/). 